\title{
Cross-sectional return dispersion and volatility prediction
}

Tianlun Fei, Xiaoquan Liu, Conghua Wen

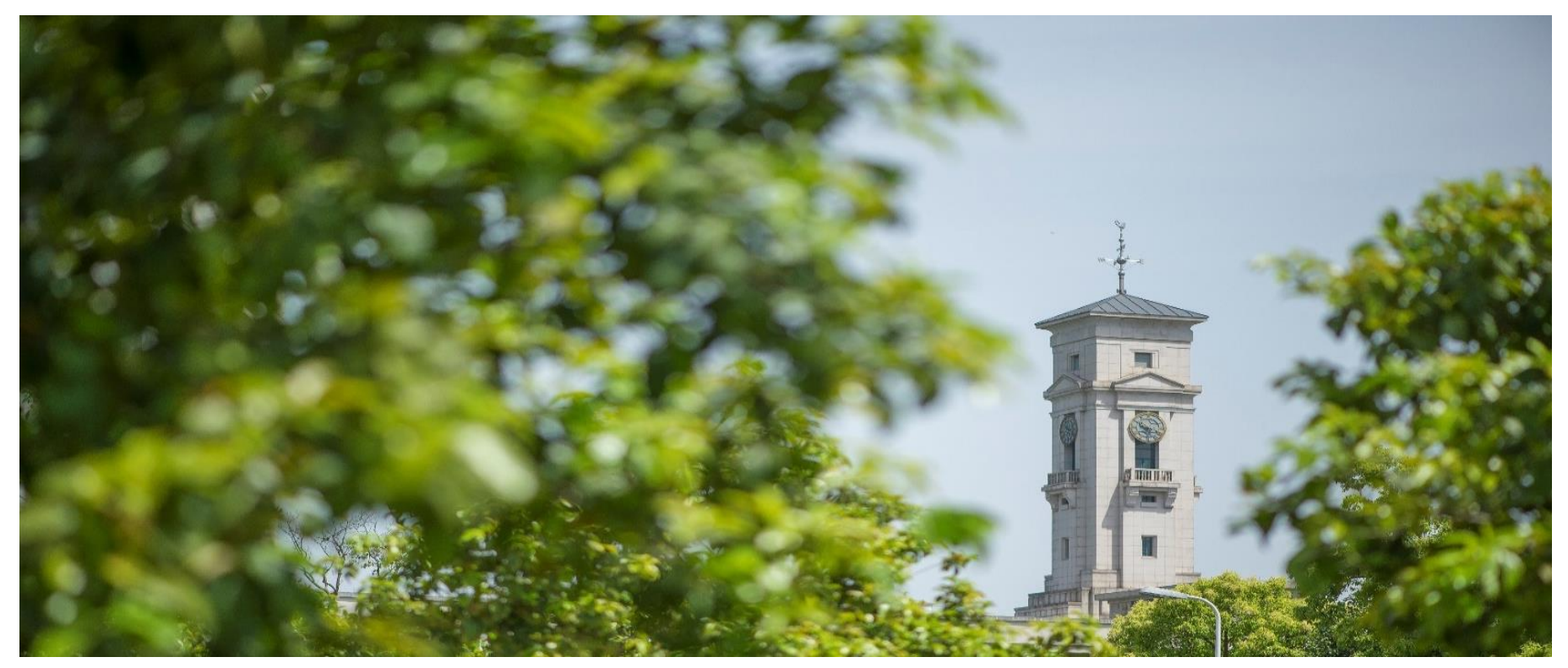


Faculty of Science and Engineering, University of Nottingham Ningbo China, 199 Taikang East Road, Ningbo, 315100, Zhejiang, China.

First published 2019

This work is made available under the terms of the Creative Commons Attribution 4.0 International License:

http://creativecommons.org/licenses/by/4.0

The work is licenced to the University of Nottingham Ningbo China under the Global University Publication Licence:

https://www.nottingham.edu.cn/en/library/documents/researchsupport/global-university-publications-licence.pdf 


\title{
Cross-sectional return dispersion and volatility prediction
}

\author{
Tianlun Fei* Xiaoquan Liu ${ }^{\dagger} \quad$ Conghua Wen ${ }^{\ddagger}$
}

September, 2019

\begin{abstract}
We use intraday and daily data to examine the impact of cross-sectional return dispersion on volatility forecasting in the Chinese equity market. We adopt the GARCH, GJR-GARCH, and HAR models and, by augmenting them with return dispersion measures, provide empirical evidence that the return dispersion exhibits substantial information in describing the volatility dynamics by generating significantly lower forecasting errors at market and industry levels. Furthermore, the information content of the return dispersion tends to offer economic gain to a mean-variance utility investor. The findings are robust with respect to alternative volatility proxies, subsample analysis, and alternative market-wide stock indices.
\end{abstract}

JEL code: G11, G17.

Keywords: Industry Effect; Chinese CSI Index; Herding; Financial Markets.

*University of Nottingham Ningbo China. Email: tianlun.fei@nottingham.edu.cn.

${ }^{\dagger}$ Corresponding author. University of Nottingham Ningbo China. Email: xiaoquan.liu@notting-ham.edu.cn. Phone: +8657488180000 Ext 8207.

${ }^{\ddagger}$ Xi’an Jiaotong-Liverpool University, China. Email: conghua.wen@xjtlu.edu.cn. 


\section{Introduction}

In this paper, we explore the information content of the cross-sectional dispersion of stock returns for the purpose of volatility prediction. Specifically, we are interested in testing whether the information contained in return dispersion, when incorporated in volatility models, is able to generate marketand industry-level forecasts that are more accurate statistically and, if so, whether these forecasts offer economic value to investors.

Our paper is motivated by the existing literature that examines the role of return dispersion in financial markets. With regard to volatility, Stivers (2003) and Connolly and Stivers (2006) clearly outline economic channels through which firm return dispersion impacts on future aggregate volatility. First, from an economic perspective, the literature shows that return dispersion is related to the macroeconomic environment and influences activities such as unemployment (Loungani et al., 1990), economic expansion and recessions (Duffee, 2001), and financial integration (Bekaert and Harvey, 1997). The evidence suggests that stock return dispersion is likely to contain information for describing future state of the economy, part of which is captured by market volatility.

Another possible channel is the interpretation of return dispersion as an indicator of herding in equity markets. Low cross-sectional dispersion implies that investors, both retail and institutional, follow each other in and out of the same stocks due to information cascade or behavioral biases especially during extreme market conditions (Chang et al., 2000; Choi and Sias, 2009; Christie and Huang, 1995; Lakonishok et al., 1992; Li et al., 2017; Yao et al., 2014). This underscores another inherent link between return dispersion and market volatility (Angelidis et al., 2015).

Finally, from a statistical perspective, Campbell et al. (2001) disaggregate volatility into the market, industry, and stock components and document that firm-level volatility does not move in tandem with the time-variation in market volatility. This implies that return dispersion, which measures dispersion in the cross section of individual stock returns, may offer incremental information for the future time series of market volatility. 
In addition to forecasting market volatility, we are equally interested in volatility prediction at the industry level. In the asset pricing literature, stock returns are shown to contain an industryspecific component orthogonal to the market or the firm (Moskowitz and Grinblatt, 1999), and industry characteristics play an important role in explaining asset returns and asset allocation (Cavaglia et al., 2000; Choi and Sias, 2009; Diermeier and Solnik, 2001; Liu et al., 2014). With regard to volatility modeling, Campbell et al. (2001) note that the time series variation in volatility is more stable at the industry level compared to that at the market or the firm level; and across industries, substantial distinctions exist in the volatility dynamics. This motivates us to study whether the information in return dispersion is equally useful for predicting volatility at the industry level.

In this paper, we focus on the Chinese equity market, an important emerging market in the global financial arena. Despite its rapid growth in size - becoming the second largest equity market with a capitalization of over $\$ 7$ trillion within three decades (Carpenter and Whitelaw, 2017) it is still young and volatile (Jun et al., 2014), and its disproportionately large number of retail investors exhibit strong behavior biases such as the disposition effect, overconfidence, and herding (Chen et al., 2014; Feng and Seasholes, 2005; Hilliard and Zhang, 2015; Kim and Nofsinger, 2008; Tan et al., 2008; Yao et al., 2014). Based on these characteristics and subsequent trading patterns, we expect the return dispersion to contain rich information and exhibit substantial impact on the volatility dynamics in this emerging market. Hence, our paper extends the literature that focuses primarily on developed equity markets such as the US and UK in incorporating additional factors in volatility prediction (Byun, 2016; Hwang and Satchell, 2005; Stivers, 2003), and the literature that explores asset pricing implication of the dispersion measure (Chen et al., 2015; Maio, 2016).

We use daily data of component stocks in the Chinese CSI 300 index to construct equally- and value-weighted cross-sectional dispersion measures: the cross-sectional standard deviation (CSSD) and the cross-sectional absolute deviation (CSAD) following Chang et al. (2000). ${ }^{1}$ We also form

\footnotetext{
${ }^{1}$ The CSI 300 index, launched in April 2005, represents the most widely followed and comprehensive index in the Chinese stock market. Component stocks are chosen based on their market capitalization and liquidity from both
} 
equally- and value-weighted portfolio-based CSSD that avoids the influence of extreme stock returns (Maio, 2016; Stivers and Sun, 2010). Furthermore, eight industry indices are constructed via a value-weighting scheme from component stocks when there are at least six component stocks in that industry at any point. In terms of volatility models, in addition to the popular generalized autoregressive conditional heteroskedasticity model (GARCH) of Bollerslev (1986) and Engle (1982), we also implement the asymmetric GARCH (GJR-GARCH) model of Glosten et al. (1993), and the heterogeneous autoregressive (HAR) realized volatility model of Corsi (2009). We augment these traditional models with CSSD and CSAD measures to test the potential forecasting capability of these measures. Our sample period is from 1 August, 2005, to 30 September, 2017.

Our empirical analysis reveals a host of interesting findings. First, the in-sample analysis shows a significant improvement for GARCH-X, GJR-GARCH-X, and HAR-X models when the CSSD and CSAD measures are incorporated. The coefficient for the CSSD/CSAD is positive and significant for the augmented models, implying that a relatively low dispersion is associated with a lower volatility. The results are consistent with findings in Hwang and Satchell (2005) and Byun (2016) that adding information in the cross-sectional dispersion helps better specify the daily volatility process. They are also in line with the evidence in Angelidis et al. (2015), Connolly and Stivers (2006), and Stivers (2003), which document a positive relation between dispersion measures and future market-level volatility. The implication is that a higher dispersion measure is linked to a higher market volatility, indicating a deterioration of financial conditions.

Second, our out-of-sample forecasting results show that, by adding the dispersion measures in augmented models, the performance of volatility forecasts is substantially improved for the CSI 300 index. The Diebold and Mariano (1995) test reveals that the augmented models, in particular the GJR-GARCH-X model, produce significantly smaller prediction errors for the majority of volatility model and dispersion combinations. Furthermore, the adjusted $R^{2}$ of the Mincer and Zarnowitz regression (Mincer and Zarnowitz, 1969) points to better model fit for the augmented models. This the Shanghai Stock Exchange and Shenzhen Stock Exchange. The index is re-balanced every six months. 
result, however, is different from Hwang and Satchell (2005) using the FTSE 350 and S\&P 500 indices or Byun (2016) with the S\&P 500 data. This could result from different markets, sample periods, or methodology.

Third, for industry-level volatility forecasts, there is a clear variation across industries over the one-day ahead horizon. We observe that volatility forecasts from augmented models are significantly improved for some sectors but fare poorly for others. However, over five- and 22-day ahead horizons, the HAR-X model improves substantially across most industries in offering statistically more precise volatility predictions.

Finally, we perform portfolio exercise to study whether statistically more precise volatility forecasts add economic value to a mean-variance utility investor who allocates her wealth between the CSI 300 index and the riskfree assets. We examine two alternative levels of investor risk aversion and report annualized portfolio returns, the Sharpe ratio, and the manipulation-proof portfolio measure (MPPM) of Goetzmann et al. (2007). Results are mixed as we examine different levels of risk aversion, different measures for return dispersion, and different volatility models. However, volatility predictions from augmented models consistently offer more economic value than benchmark models if we focus on the MPPM. Further robustness check shows that our results in the in-sample estimation and out-of-sample forecasts remain qualitatively the same with different volatility proxies, subsample analysis, and different market-wide equity indices.

The contribution of our paper, as well as its novelty, lies in its comprehensive examination of the statistical and economic value of return dispersion in predicting volatility in an important emerging market. As the return dispersion reflects the degree to which traders follow market movements rather than their own belief, it captures the expectation of future price variations useful for volatility prediction. Our paper points to a clear channel for achieving this when the cross-sectional dispersion measure appears in the variance equation for the volatility dynamics. It thus sheds new light on the causes and consequences of asset volatility. 
Our paper is related to Byun (2016), Hwang and Satchell (2005), and Stivers (2003), all of which examine the impact of return dispersion on volatility modeling in the US and/or UK markets. Our paper differs from these studies in a number of methodological specifications. First, we implement the GARCH, GJR-GARCH, and the HAR models whereas only the GARCH model is adopted in these studies; second, we use six different measures of stock return dispersion, which is more comprehensive; third and importantly, we explore the relation between stock dispersion and volatility in the biggest emerging market when these studies focus on the US and UK equity markets; and finally, we examine volatility forecasts both in statistical and economic terms, whereas the economic value of volatility forecasts is not considered in these related papers.

The rest of the paper is organized as follows. Section 2 outlines the methodology to construct cross-sectional dispersion measures, and introduces volatility models and their performance evaluation metrics. Section 3 describes data, undertakes empirical analysis, and performs robustness check. Finally, Section 4 concludes.

\section{Methodology}

In this section, we introduce the cross-sectional stock dispersion measures, outline the GARCH, GJR-GARCH, and HAR volatility models, describe proxy for the latent volatility dynamics based on intraday stock data, and summarize statistical and economic metrics for assessing volatility forecasts.

\subsection{Cross-sectional dispersion measures}

\section{$\underline{\text { Equally-weighted dispersion measures }}$}

We adopt two measures of the cross-sectional dispersion constructed from individual stocks

following Christie and Huang (1995). The first measure is the cross-sectional standard deviation 
(CSSD) defined as follows:

$$
\mathrm{CSSD}_{\mathrm{ew}, \mathrm{t}}=\sqrt{\sum_{i=1}^{N}\left(r_{i, t}-r_{m, t}\right)^{2} /(N-1)} .
$$

The second measure is the cross-sectional absolute deviation (CSAD) defined as follows:

$$
\mathrm{CSAD}_{\mathrm{ew}, \mathrm{t}}=\sum_{i=1}^{N}\left|r_{i, t}-r_{m, t}\right| / N
$$

In both equations, $r_{i, t}$ is the return to stock $i$ on day $t$, and $r_{m, t}$ is the cross-sectional average return of $N$ stocks in the portfolio on day $t$.

Value-weighted dispersion measures

In addition to the two equally-weighted cross-sectional dispersion measures, we also follow Angelidis et al. (2015) and compute the market capitalization-weighted CSSD and CSAD as follows:

$$
\begin{gathered}
\operatorname{CSSD}_{\mathrm{vw}, \mathrm{t}}=\sqrt{\sum_{i=1}^{N} w_{i, t}\left(r_{i, t}-r_{m, t}\right)^{2}} \\
\mathrm{CSAD}_{\mathrm{vw}, \mathrm{t}}=\sum_{i=1}^{N} w_{i, t}\left|r_{i, t}-r_{m, t}\right|
\end{gathered}
$$

where $w_{i, t}$ is the ratio between the market capitalization of stock $i$ and the total market capitalization at time $t$-1, a predetermined weight for stock $t$ over period $t$.

$\underline{\text { Portfolio-based dispersion measures }}$

Furthermore, we create portfolio-based CSSD following Angelidis et al. (2015), Maio (2016), and Stivers and Sun (2010). This portfolio-level dispersion measure is shown to be less noisy and performs better than firm-level ones because it mitigates the influence of extreme individual returns. We follow Maio (2016) to form 25 size- and BM-sorted portfolios from CSI component stocks based on which daily portfolio returns are evaluated and used to construct equally- and value-weighted 
CSSD.

\subsection{Volatility models}

\section{(GJR-)GARCH and (GJR-)GARCH-X models}

For the GARCH model, we implement the most parsimonious $\operatorname{ARMA}(1,1)-\operatorname{GARCH}(1,1)$ specification as follows:

$$
\begin{aligned}
r_{t} & =\mu+\gamma r_{t-1}+\varepsilon_{t}+\theta \varepsilon_{t-1}, \quad \varepsilon_{t} \| \Omega_{t-1} \sim D_{v}\left(0, h_{t}\right) \\
\sigma_{t}^{2} & =\omega+\alpha \varepsilon_{t-1}^{2}+\beta \sigma_{t-1}^{2}
\end{aligned}
$$

where the error term $\varepsilon_{t, n}$ follows a normal distribution $D_{v}$ with zero mean and variance $\sigma_{t}^{2}$ with $v$ degrees of freedom conditional on the information set $\Omega_{t-1}$.

In addition, we also consider the asymmetric properties of volatility and implement the GJRGARCH(1,1) model of Glosten et al. (1993) specified as follows:

$$
\begin{aligned}
& r_{t}=\mu+\phi_{1} r_{t-1}+\varepsilon_{t}+\phi_{2} \varepsilon_{t-1}, \quad \varepsilon_{t} \| \Omega_{t-1} \sim D_{v}\left(0, h_{t}\right) \\
& \sigma_{t}^{2}=\omega+\left(\alpha+\gamma I_{t-1}\right) \varepsilon_{t-1}^{2}+\beta \sigma_{t-1}^{2}
\end{aligned}
$$

where

$$
I_{t-1}:= \begin{cases}0, & \text { if } r_{t-1} \geq \mu, \\ 1, & \text { if } r_{t-1}<\mu .\end{cases}
$$

The indicator function $I_{t-1}$ captures the leverage effect. When the coefficient $\gamma=0$, the GJR$\operatorname{GARCH}(1,1)$ reduces to the standard $\operatorname{GARCH}(1,1)$ model.

To incorporate cross-sectional dispersion measures into the (GJR-)GARCH model, we modify 
the variance equation to produce out-of-sample volatility forecasts as follows:

$$
\sigma_{t}^{2}=\omega+\left(\alpha+\gamma I_{t-1}\right) \varepsilon_{t-1}^{2}+\beta \sigma_{t-1}^{2}+\theta H_{t-1}^{k}
$$

where $H_{t}^{k}$ represents daily, weekly, or monthly cross-sectional dispersion variable on day $t$ over horizon $k$ and is computed as a simple average of daily CSSD and CSAD:

$$
\begin{aligned}
H_{t}^{d} & =\mathrm{CSD}_{t}, \\
H_{t}^{w} & =\frac{1}{5}\left(\mathrm{CSD}_{t}+\mathrm{CSD}_{t-1}+\cdots+\mathrm{CSD}_{t-4}\right), \\
H_{t}^{m} & =\frac{1}{22}\left(\mathrm{CSD}_{t}+\mathrm{CSD}_{t-1}+\cdots+\mathrm{CSD}_{t-21}\right),
\end{aligned}
$$

where $\mathrm{CSD}_{t}$ is either CSSD or CSAD on day $t$.

\section{$\underline{\text { HAR and HAR-X model }}$}

The third model we adopt is the popular heterogeneous autoregressive (HAR) model of realized volatility proposed by Corsi (2009). Müller et al. (1993) document a strong seasonality and autoregressive heteroskedasticity of the foreign exchange market due to non-homogeneous market participants, which supports the Heterogeneous Market Hypothesis (HMH). This hypothesis proposes different trading behavior by market participants due to their difference in risk preferences, constraints and the way information is interpreted. The HAR model is designed to capture these behaviors by constructing a multi-component volatility structure. It is also able to capture stylized observations of time series volatility dynamics such as long memory. It is specified as follows:

$$
R V_{t, t+h}=\alpha+\beta_{d} Z_{t}^{d}+\beta_{w} Z_{t}^{w}+\beta_{m} Z_{t}^{m}+\varepsilon_{t+h},
$$

where $Z_{t}^{d}, Z_{t}^{w}, Z_{t}^{m}$ denote the daily, weekly and monthly volatility components on day $t$, which are 
given by the simple average as follows:

$$
\begin{aligned}
Z_{t}^{d} & =R V_{t}^{d} \\
Z_{t}^{w} & =\frac{1}{5}\left(R V_{t}^{d}+R V_{t-1}^{d}+\cdots+R V_{t-4}^{d}\right) \\
Z_{t}^{m} & =\frac{1}{22}\left(R V_{t}^{d}+R V_{t-1}^{d}+\cdots+R V_{t-21}^{d}\right) .
\end{aligned}
$$

$R V_{t}^{d}$ represents the 5-minute realized volatility computed in equation (16); $R V_{t, t+h}$ on the left-hand side of equation (11) is the day $h(h=1,5,22) 5$-minute ahead realized volatility, representing the volatility 1,5 , and 22 days ahead.

A number of studies include additional components into the HAR model and report improved empirical performance, such as the leverage effect (Corsi and Reno, 2012), jumps (Anderson and Vahid, 2007), and lunch-break returns (Wang et al., 2015). In this paper, we include the dispersion measures into the HAR model and form a HAR-X model as follows:

$$
R V_{t, t+h}=\alpha+\beta_{d} Z_{t}^{d}+\beta_{w} Z_{t}^{w}+\beta_{m} Z_{t}^{m}+\theta H_{t}^{k}+\varepsilon_{t+h},
$$

where $H_{t}^{k}$ represents daily, weekly, or monthly cross-sectional dispersion variable defined above in equations (8)-(10).

\subsection{Proxy for volatility dynamics}

Since volatility is a latent variable that cannot be observed, we follow Andersen and Bollerslev (1998) and construct realized volatility (RV) based on 5-minutes return series as proxy for the true volatility process. RV is a widely used non-parametric volatility estimator (see Andersen et al., 1999; Bandi and Russell, 2006; Chortareas et al., 2011, for example). It is easy to implement and 
can be constructed by aggregating intraday squared returns as follows:

$$
\sigma_{r v, t}^{2}=\sum_{n=1}^{N} r_{t, n}^{2},
$$

where $\sigma_{r v, t}^{2}$ is the day $t$ realized variance, and $r_{t, n}^{2}(n=1,2, \cdots, N t h)$ is the 5 -minute squared return on day $t$ where $r_{t, n}=\ln P_{t, n}-\ln P_{t, n-1}$. We use this proxy to evaluate precision of out-of-sample volatility forecasts of alternative models.

\subsection{Evaluation metrics}

We use the first 1000 days, approximately one-third of the sample period, for the in-sample estimation and the remaining data for the out-of-sample prediction via a one-day rolling scheme. The forecasting accuracy is evaluated using three popular loss functions: the root mean squared error (RMSE), the mean absolute percentage error (MAPE), and the mean absolute error (MAE). They are defined as follows:

$$
\begin{aligned}
\mathrm{RMSE} & =\sqrt{\frac{1}{T} \sum_{t=1}^{T}\left(\hat{\sigma}_{t+h}^{2}-\sigma_{t+h}^{2}\right)^{2},} \\
\mathrm{MAPE} & =\frac{100}{T} \sum_{t=1}^{T}\left|\frac{\hat{\sigma}_{t+h}^{2}-\sigma_{t+h}^{2}}{\sigma_{t+h}^{2}}\right|, \\
\mathrm{MAE} & =\frac{1}{T} \sum_{t=1}^{T}\left|\hat{\sigma}_{t+h}^{2}-\sigma_{t+h}^{2}\right|,
\end{aligned}
$$

where $T$ is the number of days in the out-of-sample period, $\hat{\sigma}_{t+h}^{2}$ is the forecasted variance over horizon $h$, and $\sigma_{t+h}^{2}$ is the proxy for true variance.

To assess the precision of volatility forecasts, we implement the Diebold and Mariano (1995) test because a smaller forecasting error does not necessarily indicate significantly improved volatility

predictions. The Diebold-Mariano test conducts a pairwise comparison to determine whether the difference between two forecast errors is statistically significant. The test statistic is defined as 
follows:

$$
D M=\frac{\bar{d}}{\sqrt{\widehat{L R V}_{\bar{d}} / T}},
$$

where $\bar{d}$ is the mean of the loss differential process $\left\{d_{t}\right\}_{t_{0}}^{T}$, and $L R V_{\bar{d}}=\gamma_{0}+2 \sum_{j=1}^{\infty} \gamma_{j}, \gamma_{j}=$ $\operatorname{cov}\left(d_{t}, d_{t-j}\right)$. The null hypothesis is that the forecasting difference is equal to zero.

Furthermore, we follow Andersen and Bollerslev (1998) and Wang et al. (2015) and conduct the Mincer-Zarnowitz regression test (Mincer and Zarnowitz, 1969). Known as the predictive power test, it is specified as follows:

$$
\sigma_{t+h}^{2}=\alpha+\beta \hat{\sigma}_{t+h}^{2}+\varepsilon_{t+h}
$$

where $\sigma_{t+h}$ is the true volatility proxy at time $t+h$, and $\hat{\sigma}_{t+h}$ is the forecasted volatility at time $t+h$. The forecasting accuracy is captured by the adjusted $R^{2}$ that reflects the overall goodnessof-fit of the regression. The higher the adjusted $R^{2}$ of the regression, the stronger the explanatory power of volatility forecasts.

\section{$\underline{\text { Portfolio exercise }}$}

We not only investigate the statistical performance of volatility forecasts, but also assess their economic value to investors as statistically improved volatility forecasts do not necessarily deliver economic gains in a portfolio setting. Following Wang et al. (2016), we construct a mean-variance utility framework whereby an investor allocates her wealth between a portfolio of stocks and the riskfree asset with specified level of risk aversion as follows:

$$
U_{t}\left(\tilde{r}_{t}\right)=E_{t}\left(w_{t} \tilde{r}_{t}+r_{r, f}\right)-\frac{1}{2} \Gamma \operatorname{var}_{t}\left(w_{t} \tilde{r}_{t}+r_{t, f}\right)
$$

where $\tilde{r}_{t}$ and $r_{r, f}$ are the excess return to the portfolio and the risk-free asset, respectively, at time $t, w_{t}$ is the weight of the portfolio at time $t$, and $\Gamma$ is the level of investor risk aversion. By maximizing $U_{t}\left(\tilde{r}_{t}\right)$ with respect to $w_{t}$, we obtain the ex ante optimal weight, $w_{t}^{*}$, at time $t+1$ given 
the excess return forecast $\hat{r}_{t+1}$, and the volatility forecast $\hat{\sigma}_{t+1}$ :

$$
w_{t}^{*}=\frac{1}{\Gamma}\left(\frac{\hat{r}_{t+1}}{\hat{\sigma}_{t+1}^{2}}\right)
$$

The return forecasts, $\hat{r}_{t+1}$, are proxied by the historical average following Neely et al. (2014) and Rapach et al. (2010). Furthermore, we pose restrictions on the optimal weight in order to rule out short sale and more than $50 \%$ leverage so that $0 \leq w_{t}^{*} \leq 1.5$. As a result, portfolio returns to a risk averse investor at time $t+1$ can be written as $R_{t+1}=w_{t}^{*} r_{t+1}+r_{t+1, f}$.

We evaluate the portfolio performance using the Sharpe ratio $(\mathrm{SR}), \mathrm{SR}_{p}=\frac{\hat{\mu}_{p}}{\hat{\sigma}_{p}}$ and the manipulationproof performance measures (MPPM) (Goetzmann et al., 2007) in addition to overall portfolio excess returns, where $\hat{\mu}_{p}$ and $\hat{\sigma}_{p}$ are the mean and standard deviation of portfolio returns. The MPPM is expressed as follows:

$$
\Theta=\frac{1}{(1-\Gamma) \Delta t} \ln \left(\frac{1}{T} \sum_{t=1}^{T}\left[\left(1+\bar{r}_{t}\right) /\left(1+r_{f, t}\right)\right]^{1-\Gamma}\right)
$$

where $\bar{r}_{t}$ is portfolio un-annualized rate of return at time $t, T$ is the number of observations, and $\Delta t$ is the time interval between two observations. The use of the MPPM is particularly powerful in performance measurement as it avoids manipulation especially by hedge fund managers whose compensation package is based on fund performance.

\section{Data and empirical analysis}

Our intraday and daily data come from the China Security Market Trade \& Quote (Level 1) of the China Stock Market \& Accounting Research (CSMAR) database. They include all 300 component stocks as well as the CSI 300 index itself with stock ID, tick prices, date, and time. The sample period is from 1 August 2005 to 30 September 2017.

Table 1 summarizes the descriptive statistics of selected stocks from the sample. The number 
of daily observations ranges from 2757 to 3038 due to different starting dates and stock suspensions during the sample period. The mean and median of daily returns are positive for most stocks with mostly positive skewness and excess kurtosis. The last column reports the number of observations for intraday data, which is used to calculate the proxy for latent volatility dynamics. It is interesting to note that the stocks in our sample vary in terms of market value that ranges from RMB 25 billion for the non-ferrous metal producer NONFEMET to RMB 319 billion for the giant carmaker SAIC. Firms also differ in their book-to-market ratio and turnover. Hence, our sample stocks provide a good spread of firms in the Chinese equity market.

To investigate the information content of the cross-sectional dispersion at the industry level, we tabulate the industrial classification in Table 2 alongside the number of stocks in each industry. We require an industry to have at least six firms to be included in our empirical exercise to avoid potential small sample bias. Hence, we focus on the following eight industries: (1) Mining (B); (2) Manufacturing (C); (3) Utilities (D); (4) Wholesale and retail (F); (5) Transportation, storage and post (G); (6) Information technology (I); (7) Finance (J); and (8) Real estate (K). We construct industry equally- and value-weighted 5-min RV using 5-minute stock returns for the out-of-sample volatility forecasting exercises.

Table 3 describes the time series of cross-sectional dispersion measures CSSD and CSAD. The two measures are weakly correlated with the realized volatility of the CSI index as can be seen from the last column of the table, but highly correlated with each other with a significant correlation of 0.99, which can be viewed from Figure 1. The two measures move in tandem with each other but much less so with the CSI 300 index except during the stock market crash in autumn 2015 and early 2016 when the two measures go up and down very much in line with the market index. This suggests the existence of herding during the crash period. 


\subsection{In-sample volatility estimation}

Table 4 reports the in-sample volatility estimation result of the benchmark and augmented models for the CSI 300 index over the full sample period. The $\mathrm{X}$ variable is the CSSD and CSAD, both equally and value-weighted from individual stocks, and equally and value-weighted CSSD based on size- and BM-sorted portfolios, that capture the cross section of stock return dispersion.

First, we observe that the maximum likelihood values of GARCH-X and GJR-GARCH-X models with CSSD and CSAD are higher than that of the benchmark GARCH and GJR-GARCH models, and the differences are highly significant at the $1 \%$ level. For example, the maximum likelihood value is 8116 for the GARCH-X with value-weighted CSAD in Panel A but 8107 for the GARCH model. This suggests a much improved goodness-of-fit with the additional dispersion measure and underlines its information content. Second, we note that the $\theta$ coefficient is highly significant for the augmented models, indicating that the dispersion measure plays a substantial role in describing daily volatility process. This result is consistent with the findings of Hwang and Satchell (2005) and Byun (2016) that incorporating the cross-sectional dispersion is able to improve daily and monthly return volatility specification, respectively. It also implies that, at the market level, a relatively high return dispersion predicts a high future market volatility and vice versa. This result is in line with Angelidis et al. (2015), Stivers (2003) and Connolly and Stivers (2006), all of which document a positive relation between the cross-sectional stock return dispersion and future market-level volatility.

A similar pattern can be observed when we implement the HAR and HAR-X models in Panel C. In this panel, the $\theta$ coefficient is also positive and highly significant at the $1 \%$ level across different dispersion measures, consistent with results in Panels A and B. This also implies that a relatively large cross-sectional dispersion predicts a high future market volatility, in line with the implication from the GARCH and GJR-GARCH models. Furthermore, we note that the adjusted $R^{2}$ is improved from 0.659 for the HAR model to between 0.662 and 0.665 for the HAR-X models. 


\subsection{Out-of-sample forecasting}

As the in-sample parameter significance does not always translate to out-of-sample forecasting improvement, we conduct a number of out-of-sample tests at the market and industry levels to examine the forecasting performance of benchmark and augmented models. Table 5 summarizes volatility prediction results for the CSI 300 index. We report three loss functions of forecasting errors: RMSE, MAPE and MAE, and perform the Diebold and Mariano (1995) pairwise comparison to evaluate whether the difference in forecasting performance between volatility models is significant. We also show the adjusted $R^{2}$ of the Mincer-Zarnowitz regression.

For the two GARCH models in Panels A and B, the results suggest that the forecasting performance of augmented models is usually significantly better than that of benchmark ones for both the RMSE and MAE. For example, the Diebold and Mariano $t$-statistic for the difference in forecasting error is 4.36 and 5.68 when the GJR-GARCH is augmented by the value-weighted CSSD and CSAD, respectively, as measured by the MAE in Panel B. The Mincer-Zarnowitz adjusted $R^{2}$ also improves from 0.34 to 0.44 and 0.45 when value-weighted CSSD or CSAD, respectively, is added to the model. Meanwhile, we notice that when the portfolio-based CSSD is added to the GARCH model in Panel A, the MAPE significantly increases. It is interesting to note that the improvement generated by the GJR-GARCH-X model relative to the GJR-GARCH is more evident compared with the improvement of the GARCH-X relative to the GARCH model.

Results are similar for the HAR and HAR-X models in Panel C. We conduct forecasting exercises over one-, five-, and 22-day ahead horizons to correspond to different volatility components underlying the HAR model. By adding different measures of cross-sectional dispersion, the augmented models exhibit reduced forecasting error, in many cases significant at the $1 \%$ level. For example, over 22-day ahead horizon, the $t$-statistic of the Diebold-Mariano test for the RMSE is always significant at the $1 \%$ level regardless of the specific cross-sectional dispersion measure. Moreover, according to the adjusted $R^{2}$ of the Mincer-Zarnowitz regression, the augmented HAR-X 
model exhibits stronger explanatory power with higher $R^{2}$ except for one case.

Overall, at the aggregate market level, we provide clear evidence that the information content in the cross-sectional stock return dispersion helps improve the forecasting performance of the benchmark models. This finding is different from the evidence in Hwang and Satchell (2005) and Byun (2016) perhaps due to different methodology or the test market. It is worth noting that the equally-weighted CSSD and CSAD seem to capture more information and thus are better at helping to generate more precise volatility forecasts. ${ }^{2}$

At the industry level, we construct eight industry indices from intraday component stock returns based on the value-weighting scheme and report out-of-sample forecasting performance in Table 6 with the six cross-sectional dispersion measures. ${ }^{3}$ In this table, it is noteworthy that, at the industry level, the performance of GARCH-X and GJR-GARCH-X models are rather mixed cross the industries. The augmented models tend to perform significantly better for the finance industry but significantly worse for the mining, manufacturing, and utilities industries. For the HAR models in Panel C, however, the HAR-X model tends to outperform the benchmark over all industries and dispersion measures, especially over the 22-day ahead horizon.

Taken together, results in this table suggest that the information content of the cross-sectional dispersion is more pronounced at the weekly and monthly horizons, and that it represents a useful source of information for some industries as far as volatility prediction is concerned. We note that at the industry level, volatility prediction with the dispersion measure does not work well over the next day. One possible way to rationalize this relates to the use of CSSD/CSAD in detecting herding in equity markets (Chiang and Zheng, 2010; Christie and Huang, 1995; Tan et al., 2008) and at the industry level (Lee et al., 2013). Choi and Sias (2009) argue that as institutional investors receive industry signals at different times, they act on signals and trade sequentially. As a result,

\footnotetext{
${ }^{2}$ We conjecture that this is in the spirit of Timmermann (2006) and Rapach et al. (2010), which show that the simple $1 / \mathrm{N}$-weighting scheme outperforms more sophisticated weights in the presence of complex and evolving data-generating processes.

${ }^{3}$ We only report the RMSE and the corresponding $t$-statistics for the Diebold and Mariano test to conserve space. Results based on the MAPE and MAE are available upon request from the authors.
} 
we are more likely to observe forecasting advantage at the industry level over weekly and monthly horizons.

\subsection{Economic value}

Statistical improvement does not necessarily lead to economic gains to investors when volatility predictions are used in trading strategies. Hence, we conduct a simple portfolio exercise to gauge the economic value of volatility forecasts for augmented GARCH-X, GJR-GARCH-X, and HAR-X models. As we assume that expected returns to individual assets are the same as their historical average, overall portfolio returns as well as weight for the stock portfolio hinge upon the accuracy of volatility forecasts and investor risk aversion.

In Table 7, we summarize average annualized portfolio returns, the Sharpe ratio, and the manipulation-proof performance measure (MPPM) at the market level with two different risk aversion levels and different dispersion measures. Results are quite mixed. If we focus on the Sharpe ratio, when $\Gamma=6$ for moderate investor risk aversion, in six out of nine cases the augmented models exhibit higher Sharpe ratio than the corresponding benchmark models, whereas for $\Gamma=9$, the benchmark model dominates in generating higher portfolio returns. However, when we move to the MPPM, we notice that for all combinations of volatility model and dispersion measure, the augmented model shows higher MPPM value. This suggests that the information contained in stock return dispersion tends to add value to investors in a portfolio exercise.

\subsection{Robustness check}

We conduct three robustness tests to show that our baseline results discussed above are not due to specific choices we make in terms of methodology, sample period, or the test asset. In the first test, we use different proxies for the latent volatility process; in the second robustness check, we break the sample period into two and perform subsample analysis; finally, we examine the performance 
of two other market-wide indices: the Shanghai Stock Exchange (SSE) composite index and the Shenzhen Stock Exchange (SZSE) composite index. Our results remain qualitatively the same in these robustness tests.

\section{Different volatility proxies}

We adopt two different volatility estimators to capture the true volatility dynamics. They are the realized median of Andersen et al. (2012) and the realized range of Parkinson (1980). The realized median takes jumps in underlying returns as well as small (or zero) returns into account. It is defined as follows:

$$
\sigma_{m e d, t}^{2}=\frac{\pi}{6-4 \sqrt{3}+\pi}\left(\frac{N}{N-2}\right) \times \sum_{n=2}^{N-1} \operatorname{med}\left(\left|\Delta r_{n-1}\right|,\left|\Delta r_{n}\right|,\left|\Delta r_{n+1}\right|\right)^{2}
$$

where $r_{n}$ is the absolute return for the $n$th interval on day $t$. The realized range considers large price movements within a day that the realized volatility measure may fail to capture. Thus, it is expected to infer more information and improve upon the realized variance estimator by replacing each intraday squared return with the high-low range as follows:

$$
\sigma_{r n g, t}^{2}=\frac{1}{4 \ln 2} \sum_{n=1}^{N}\left(\ln H_{t, i}-\ln L_{t, i}\right)^{2}
$$

where $H_{t, i}$ and $L_{t, i}$ are the highest and lowest prices for the $n$th interval on day $t$. Martens and Van Dijk (2007) show that, despite market frictions, it outperforms the realized volatility in terms of forecasting accuracy. Considering large price movements in the volatile Chinese stock market and microstructure biases, these two volatility proxies represent suitable alternative proxies.

Our empirical results are summarized in Tables 8 and 9 at the market and industry level, respectively, when the realized median is used as the volatility estimator. ${ }^{4}$ In Table 8 , the performance of augmented GARCH-type models is very similar to that in Table 5, as the augmented models

\footnotetext{
${ }^{4}$ Results based on the realized range as volatility proxy are qualitatively the same. They are available from the authors upon request.
} 
outperform the benchmark models in the majority of volatility model and dispersion measure combinations and significantly better in many cases. The HAR-X model continues to dominate the HAR model in Panel $\mathrm{C}$, especially when the forecasting errors are computed via the MAPE and MAE.

At the industry level in Table 9, we again observe rather mixed results across the sectors. However, the HAR-X model tends to offer significantly reduced RMSE, especially over the fiveand 22-day ahead horizons. Taken together, when we implement the same forecasting exercises with popular alternative volatility proxies, our main findings remain unchanged: the cross-sectional dispersion of stock returns contains useful information that helps improve volatility prediction.

$\underline{\text { Subsample analysis }}$

Our second robustness test is to break the whole sample period almost equally into two: the first subsample is from August 2005 to December 2011, and the second subsample is from January 2012 to the end of the sample period. Interestingly, each subsample contains a market downturn: the Great Recession in the middle of the first subperiod, and the Chinese stock market crash of 2015/2016 during the second subsample.

The performance of the benchmark and augmented models is summarized in Tables 10 and 11, respectively, for the two subsamples. It is interesting to note that the GARCH-X, GJR-GARCH-X, and HAR-X models perform very strongly in generating significantly reduced volatility forecasts in most volatility model and dispersion measure combinations. Our results are consistent with evidence in the literature that, when the market is in agitation, investors tend to herd the market more (see Christie and Huang, 1995; Yao et al., 2014, for example), thus the dispersion measures, which capture herding in the market, are more informative and perform better in the volatility prediction exercises .

$\underline{\text { Alternative indices }}$ 
In addition to the CSI 300 index, we have also examined the SSE and SZSE composite indices, which contain 1381 and 2057 stocks, respectively, during our sample period, and tested whether cross-sectional dispersion helps generate more precise volatility forecasts in these markets. Table 12 summarizes the results for the SSE composite index. In this table, we again observe qualitatively similar results in that the dispersion measures continue to offer information content that helps reduce volatility prediction error, in many cases significantly, and improves the adjusted $R^{2}$ for the Mincer-Zarnowitz regressions. Furthermore, we have conducted the same exercise for the SZSE composite index (Table A1), and the subsample analysis for the SSE composite index (Tables A2 and A3) and the SZSE composite index (Tables A4 and A5) in the appended tables. All results attest to the importance of incorporating cross-sectional dispersion in volatility forecasting.

\section{Conclusion}

In this paper, we explore the impact of the cross-sectional stock return dispersion on volatility modeling and forecasting. Motivated by the prior theoretical and empirical evidence in the literature documenting the forecasting ability of this measure for stock returns, we are interested in investigating whether it also helps improve volatility prediction. Employing equally- and value-weighted cross-sectional standard deviation (CSSD) and cross-sectional absolute deviation (CSAD) of component stocks of the Chinese CSI 300 index, as well as the equally- and value-weighted CSSD based on size- and BM-sorted portfolios, the empirical results confirm our conjecture that, by augmenting the GARCH, GJR-GARCH, and HAR models with the dispersion measure, the augmented models offer a better fit in the in-sample estimation tests and improve out-of-sample volatility forecasting accuracy. The dispersion measure also tends to offer economic value to a mean-variance utility investor. Similar results hold when we study volatility forecasts at the industry level. Further robustness check corroborates the main findings with different volatility proxies, subsample analysis, and for SSE and SZSE composite indices. Our paper thus extends the literature by highlighting the role that cross-sectional stock return dispersion plays in modeling equity market volatility. 


\section{References}

Andersen, T.G., Bollerslev, T., 1998. Answering the skeptics: Yes, standard volatility models do provide accurate forecasts. International Economic Review 39, 885-905.

Andersen, T.G., Bollerslev, T., Diebold, F.X., Labys, P., 1999. (Understanding, optimizing, using and forecasting) Realized volatility and correlation. Working paper, Northwestern University.

Andersen, T.G., Dobrev, D., Schaumburg, E., 2012. Jump-robust volatility estimation using nearest neighbor truncation. Journal of Econometrics 169, 75-93.

Anderson, H.M., Vahid, F., 2007. Forecasting the volatility of Australian stock returns: Do common factors help? Journal of Business \& Economic Statistics 25, 76-90.

Angelidis, T., Sakkas, A., Tessaromatis, N., 2015. Stock market dispersion, the business cycle and expected factor returns. Journal of Banking \& Finance 59, 265-279.

Bandi, F.M., Russell, J.R., 2006. Separating microstructure noise from volatility. Journal of Financial Economics 79, 655-692.

Bekaert, G., Harvey, C.R., 1997. Emerging equity market volatility. Journal of Financial Economics $43,29-77$.

Bollerslev, T., 1986. Generalized autoregressive conditional heteroskedasticity. Journal of Econometrics $31,307-327$.

Byun, S.J., 2016. The usefulness of cross-sectional dispersion for forecasting aggregate stock price volatility. Journal of Empirical Finance 36, 162-180.

Campbell, J.Y., Lettau, M., Malkiel, B.G., Xu, Y., 2001. Have individual stocks become more volatile? An empirical exploration of indiosyncratic volatility. Journal of Finance 56, 1-43.

Carpenter, J.N., Whitelaw, R.F., 2017. The development of China's stock market and stakes for the global economy. Annual Review of Financial Economics 9, 233-257. 
Cavaglia, S., Brightman, C., Aked, M., 2000. The increasing importance of industry factors. Financial Analysts Journal 56, 41-54.

Chang, E.C., Cheng, J.W., Khorana, A., 2000. An examination of herd behavior in equity markets: An international perspective. Journal of Banking \& Finance 24, 1651-1679.

Chen, C.D., Demirer, R., Jategaonkar, S., 2015. Risk and return in the Chinese stock market: Does equity return dispersion proxy risk? Pacific-Basin Finance Journal 33, 23-37.

Chen, J., Jiang, F., Tu, J., 2014. Asset allocation in Chinese stock market: The role of return predictability. Journal of Portfolio Management 41, 71-83.

Chiang, T.C., Zheng, D., 2010. An empirical analysis of herd behavior in global stock markets. Journal of Banking \& Finance 34, 1911-1921.

Choi, N., Sias, R.W., 2009. Institutional industry herding. Journal of Financial Economics 94, 469-491.

Chortareas, G., Jiang, Y., Nankervis, J.C., 2011. Forecasting exchange rate volatility using highfrequency data: Is the Euro different? International Journal of Forecasting 27, 1089-1107.

Christie, W.G., Huang, R.D., 1995. Following the pied piper: Do individual returns herd around the market? Financial Analysts Journal 51, 31-37.

Connolly, R., Stivers, C., 2006. Information content and other characteristics of the daily crosssectional dispersion in stock returns. Journal of Empirical Finance 13, 79-112.

Corsi, F., 2009. A simple approximate long-memory model of realized volatility. Journal of Financial Econometrics 7, 174-196.

Corsi, F., Reno, R., 2012. Discrete-time volatility forecasting with persistent leverage effect and the link with continuous-time volatility modeling. Journal of Business \& Economic Statistics 30, $368-380$. 
Diebold, F.X., Mariano, R.S., 1995. Comparing predictive accuracy. Journal of Business \& Economic Statistics 13, 253-265.

Diermeier, J., Solnik, B., 2001. Global pricing of equity. Financial Analysts Journal 57, 37-47.

Duffee, G.R., 2001. Asymmetric cross-sectional dispersion in stock returns: Evidence and implications. Working paper, Federal Reserve Bank of San Francisco.

Engle, R.F., 1982. Autoregressive conditional heteroscedasticity with estimates of variance of United Kingdom inflation. Econometrica 50, 987-1008.

Feng, L., Seasholes, M.S., 2005. Do investor sophistication and trading experience eliminate behavioral biases in financial markets? Review of Finance 9, 305-351.

Glosten, L.R., Jagannathan, R., Runkle, D.E., 1993. On the relation between the expected value and the volatility of the nominal excess return on stocks. Journal of Finance 48, 1779-1801.

Goetzmann, W., Ingersoll, J., Spiegel, M., Welch, I., 2007. Portfolio performance manipulation and manipulation-proof performance measures. Review of Financial Studies 20, 1503-1546.

Hilliard, J., Zhang, H., 2015. Size and price-to-book effects: Evidence from the Chinese stock markets. Pacific-Basin Finance Journal 32, 40-55.

Hwang, S., Satchell, S.E., 2005. GARCH model with cross-sectional volatility: GARCHX models. Applied Financial Economics 15, 203-216.

Jun, X., Li, M., Shi, J., 2014. Volatile market condition and investor clientele effects on mutual fund flow performance relationship. Pacific-Basin Finance Journal 29, 310-334.

Kim, K.A., Nofsinger, J.R., 2008. Behavioral finance in Asia. Pacific-Basin Finance Journal 16, $1-7$.

Lakonishok, J., Shleifer, A., Vishny, R.W., 1992. The impact of institutional trading on stock prices. Journal of Financial Economics 32, 23-43. 
Lee, C.C., Chen, M.P., Hsieh, K.M., 2013. Industry herding and market states: Evidence from Chinese stock markets. Quantitative Finance 13, 1091-1113.

Li, W., Rhee, G., Wang, S., 2017. Differences in hearding: Individual vs. institutional investors. Pacific-Basin Finance Journal 45, 174-185.

Liu, X., Pong, S.Y., Shackleton, M.B., Zhang, Y., 2014. Option-implied volatilities and stock returns: Evidence from industry-neutral portfolios. Journal of Portfolio Management 41, 65-77.

Loungani, P., Rush, M., Tave, W., 1990. Stock market dispersion and unemployment. Journal of Monetary Economics 25, 367-388.

Maio, P., 2016. Cross-sectional return dispersion and the equity premium. Journal of Financial Markets 29, 87-109.

Martens, M., Van Dijk, D., 2007. Measuring volatility with the realized range. Journal of Econometrics 138, 181-207.

Mincer, J., Zarnowitz, V., 1969. The evaluation of economic forecasts, in: Economic forecasts and expectations, New York, NBER.

Moskowitz, T., Grinblatt, M., 1999. Do industries explain momentum. Journal of Finance 54, $1249-1290$.

Müller, U.A., Dacorogna, M.M., Davé, R.D., Pictet, O.V., Olsen, R.B., Ward, J.R., 1993. Fractals and intrinsic time: A challenge to econometricians. Working paper, Olsen \& Associates, Zürich.

Neely, C.J., Rapach, D.E., Tu, J., Zhou, G., 2014. Forecasting the equity risk premium: The role of technical indicators. Management Science 60, 1772-1791.

Parkinson, M., 1980. The extreme value method for estimating the variance of the rate of return. Journal of Business 53, 61-65. 
Rapach, D.E., Strauss, J.K., Zhou, G., 2010. Out-of-sample equity premium prediction: Combination forecasts and links to the real economy. Review of Financial Studies 23, 821-862.

Stivers, C., Sun, L., 2010. Cross-sectional return dispersion and time variation in value and momentum premiums. Journal of Financial and Quantitative Analysis 45, 987-1014.

Stivers, C.T., 2003. Firm-level return dispersion and the future volatility of aggregate stock market returns. Journal of Financial Markets 6, 389-411.

Tan, L., Chiang, T.C., Mason, J.R., Nelling, E., 2008. Herding behavior in Chinese stock markets: An examination of A and B shares. Pacific-Basin Finance Journal 16, 61-77.

Timmermann, A., 2006. Forecast combinations, in: Elliott, G., Granger, C.W.J., Timmermann, A. (Eds.), Handbook of Economic Forecasting. Elsevier, Amsterdam, pp. 135-196.

Wang, X., Wu, C., Xu, W., 2015. Volatility forecasting: The role of lunch-break returns, overnight returns, trading volume and leverage effects. International Journal of Forecasting 31, 609-619.

Wang, Y., Ma, F., Wei, Y., Wu, C., 2016. Forecasting realized volatility in a changing world: A dynamic model averaging approach. Journal of Banking \& Finance 64, 136-149.

Yao, J., Ma, C., He, W.P., 2014. Investor herding behaviour of Chinese stock market. International Review of Economics \& Finance 29, 12-29. 
Figure 1: The time series of the cross-sectional return dispersion

This figure shows the time series of daily equally-weighted CSSD and CSAD measures. They are constructed from component stocks of the CSI 300 index. The left axis shows the magnitude of the CSSD and CSAD, whereas the right axis is the CSI 300 index level. The sample period is from 1 August 2005 to 30 September 2017.
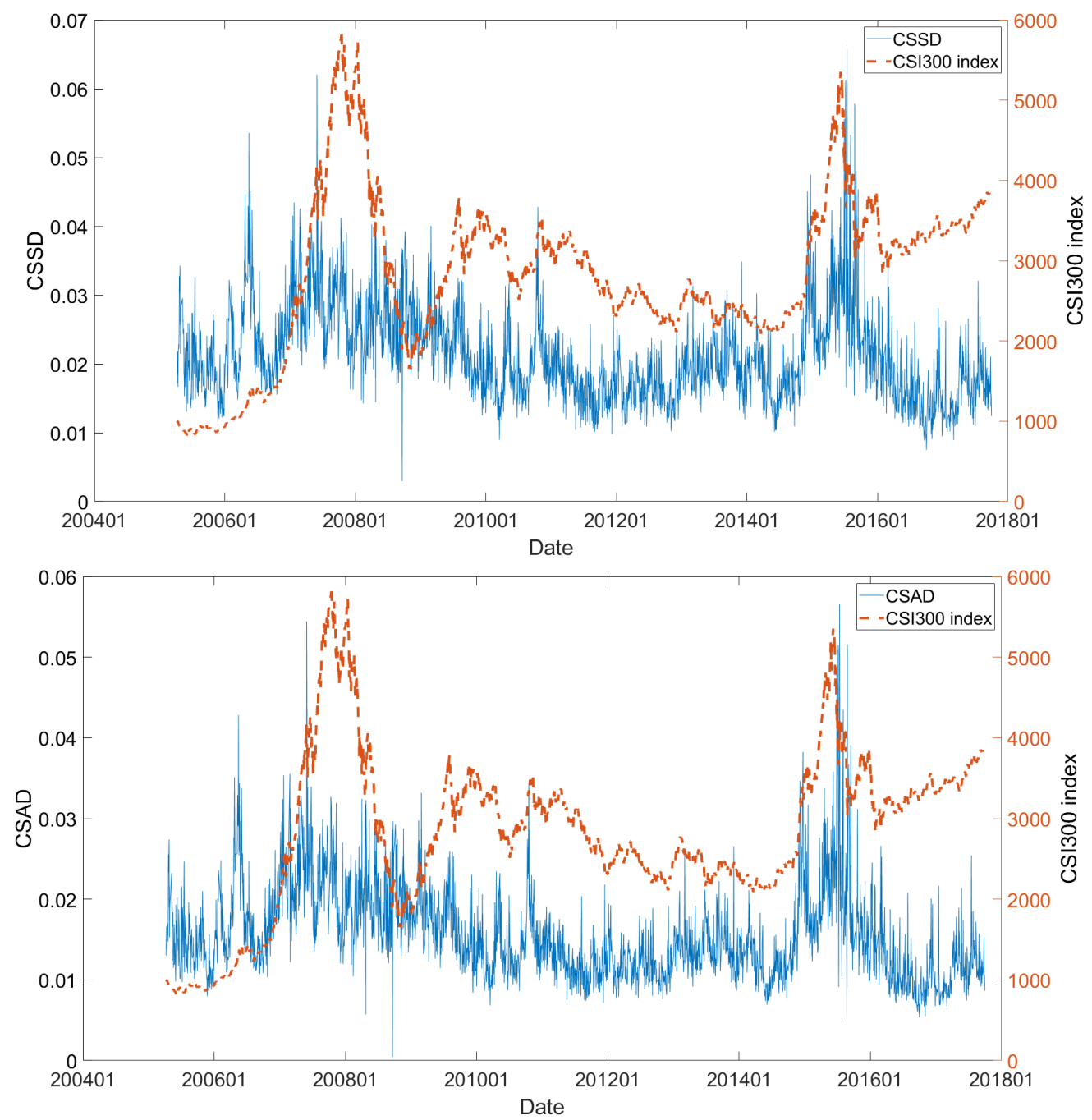
Table 1: Descriptive statistics for selected sample stocks

This table reports descriptive statistics for the CSI 300 index and selected component stocks. It summarizes the stock code, name, industry code, number of daily observations, the scaled mean, median, and standard deviation, skewness and excess kurtosis of daily returns. It also shows the Ljung-Box statistics for autocorrelation for 10 lags. The average market value (MV in 10 billion RMB), the book-to-market ratio (B/M), and turnover in percent of as 2017 are also summarized. In the last column, we report the total number of intraday observations. The sample period is from from 1 August 2005 to 30 September 2017. ${ }^{*} p<0.1 ;{ }^{* *} p<0.05 ;{ }^{* * *} p<0.01$.

\begin{tabular}{|c|c|c|c|c|c|c|c|c|c|c|c|c|c|}
\hline Code & Name & $\begin{array}{l}\text { Industry } \\
\text { Code }\end{array}$ & Daily Obs & $\begin{array}{c}\text { Mean } \\
\left(\times 10^{4}\right)\end{array}$ & $\begin{array}{c}\text { Median } \\
\left(\times 10^{4}\right)\end{array}$ & $\begin{array}{l}\text { Stdev } \\
\left(\times 10^{2}\right)\end{array}$ & Skewness & Kurtosis & $\mathrm{LB}[10]$ & MV & $\mathrm{B} / \mathrm{M}$ & Turnover & $\begin{array}{c}\text { Intraday } \\
\text { Obs }\end{array}$ \\
\hline 000300 & CSI300 & & 3038 & 4.426 & 9.984 & 1.803 & -0.537 & 6.659 & $37.53^{* * *}$ & & & & $8,053,943$ \\
\hline 000002 & VANKE & $\mathrm{K}$ & 2840 & 14.85 & 0.000 & 2.842 & 0.348 & 5.135 & 15.76 & 26.27 & 0.629 & 0.928 & $9,667,989$ \\
\hline 000009 & BAOAN & $\mathrm{S}$ & 2837 & 12.89 & 17.89 & 3.357 & -0.025 & 4.454 & $16.04^{*}$ & 1.828 & 0.444 & 3.487 & $9,198,265$ \\
\hline 000060 & NONFEMET & $\mathrm{C}$ & 2963 & 14.01 & 10.66 & 3.445 & 0.024 & 4.401 & $41.35^{* * *}$ & 2.496 & 0.319 & 3.917 & $9,411,585$ \\
\hline 000063 & ZTE & $\mathrm{C}$ & 2942 & 9.346 & 2.645 & 2.794 & 0.357 & 7.730 & $24.73^{* * *}$ & 9.841 & 0.452 & 3.529 & $9,500,170$ \\
\hline 000069 & $\mathrm{OCT}$ & $\mathrm{K}$ & 2915 & 10.45 & 0.000 & 3.032 & 0.042 & 4.875 & $45.11^{* * *}$ & 5.124 & 0.708 & 1.502 & $8,949,343$ \\
\hline 000157 & ZOOMLION & $\mathrm{C}$ & 2912 & 13.06 & 0.000 & 2.903 & 0.225 & 5.420 & $39.85^{* * *}$ & 3.500 & 1.080 & 1.299 & $9,658,432$ \\
\hline 000402 & FS & $\mathrm{K}$ & 2982 & 9.935 & 9.500 & 2.934 & 0.047 & 5.174 & $34.18^{* * *}$ & 3.422 & 0.912 & 1.721 & $9,150,438$ \\
\hline 000425 & XCMG & $\mathrm{C}$ & 2922 & 12.20 & 0.000 & 3.263 & 0.635 & 8.578 & $48.45^{* * *}$ & 2.646 & 0.776 & 2.634 & $8,776,418$ \\
\hline 000568 & LZLJ & $\mathrm{C}$ & 2933 & 16.69 & 7.790 & 2.737 & 0.267 & 5.194 & $32.47^{* * *}$ & 7.058 & 0.163 & 1.806 & $8,755,814$ \\
\hline 000625 & CHANGAN & $\mathrm{C}$ & 2812 & 13.15 & 6.455 & 3.042 & 0.258 & 4.932 & $31.77^{* * *}$ & 6.216 & 0.630 & 1.427 & $9,071,481$ \\
\hline 000630 & TNMG & $\mathrm{C}$ & 2825 & 8.453 & 0.000 & 3.121 & 0.090 & 5.785 & $26.48^{* * *}$ & 2.873 & 0.559 & 3.086 & $8,817,564$ \\
\hline 000651 & GREE & $\mathrm{C}$ & 2842 & 18.94 & 6.885 & 2.658 & 0.333 & 5.115 & $40.38^{* * *}$ & 21.51 & 0.262 & 2.836 & $8,605,026$ \\
\hline 000709 & HBIS & $\mathrm{C}$ & 2834 & 8.396 & 0.000 & 2.880 & 0.042 & 5.772 & $45.76^{* * *}$ & 4.565 & 1.034 & 5.178 & $8,956,200$ \\
\hline 600009 & SHIA & G & 3001 & 6.549 & 3.680 & 2.353 & -0.019 & 6.373 & $36.61^{* * *}$ & 3.962 & 0.333 & 1.526 & $7,099,140$ \\
\hline 600010 & $\mathrm{BSU}$ & $\mathrm{C}$ & 2938 & 9.716 & 0.000 & 2.977 & 0.330 & 5.555 & $17.36^{*}$ & 5.286 & 0.439 & 1.547 & $8,026,793$ \\
\hline 600019 & BIS & $\mathrm{C}$ & 2899 & 6.111 & 0.000 & 2.501 & 0.133 & 6.506 & $35.92^{* * *}$ & 15.89 & 0.845 & 1.000 & $7,843,187$ \\
\hline 600021 & SPIC & $\mathrm{D}$ & 2877 & 8.652 & 0.000 & 2.775 & 0.191 & 6.528 & $27.55^{* * *}$ & 2.533 & 0.626 & 1.030 & $6,650,640$ \\
\hline 600028 & SINOPEC & B & 2995 & 6.765 & 0.000 & 2.301 & 0.195 & 7.261 & $24.35^{* * *}$ & 71.90 & 1.159 & 0.239 & $8,188,145$ \\
\hline 600029 & CSA & G & 2941 & 9.297 & 0.000 & 3.115 & 0.140 & 5.213 & $50.34^{* * *}$ & 8.443 & 0.651 & 1.765 & $7,852,472$ \\
\hline 600031 & SANY & $\mathrm{C}$ & 2991 & 14.46 & 0.000 & 3.008 & 0.292 & 5.086 & $45.16^{* * *}$ & 5.842 & 0.402 & 2.281 & $7,773,123$ \\
\hline 600050 & UNICOM & I & 2902 & 7.991 & 0.000 & 2.558 & 0.363 & 6.874 & $24.02^{* * *}$ & 15.49 & 1.365 & 2.102 & $7,817,792$ \\
\hline 600085 & TRT & $\mathrm{C}$ & 3008 & 9.787 & 4.495 & 2.607 & 0.134 & 5.935 & $32.1^{* * *}$ & 4.422 & 0.274 & 1.202 & $7,101,100$ \\
\hline 600100 & THTF & $\mathrm{C}$ & 2822 & 10.91 & 14.87 & 3.260 & 0.017 & 4.634 & $21.57^{* *}$ & 2.770 & 0.668 & 2.069 & $7,242,916$ \\
\hline 600104 & SAIC & $\mathrm{C}$ & 2933 & 13.99 & 9.810 & 2.794 & 0.206 & 5.224 & $22.19^{* *}$ & 31.91 & 0.705 & 0.648 & $7,826,882$ \\
\hline 600153 & $\mathrm{CDN}$ & $\mathrm{F}$ & 2757 & 12.86 & 14.08 & 2.735 & -0.029 & 5.458 & 14.01 & 3.316 & 0.988 & 2.327 & $6,667,571$ \\
\hline 600170 & SCG & $\mathrm{E}$ & 2932 & 11.33 & 12.80 & 2.830 & 0.076 & 5.782 & $30.7^{* * *}$ & 3.234 & 0.745 & 1.285 & $7,196,133$ \\
\hline
\end{tabular}


Table 2: Industrial classification

This table summarizes industrial classification and the number of stocks in each industry for constructing industrial indices.

\begin{tabular}{llrrr} 
Industry Code & Industry Name & \multicolumn{3}{c}{ Number of stocks } \\
\cline { 3 - 5 } & & Min & Median & Max \\
\hline B & Mining & 13 & 19 & 34 \\
C & Manufacturing & 115 & 147 & 159 \\
D & Utilities & 8 & 20 & 27 \\
F & Wholesale and retail & 10 & 13 & 16 \\
G & Transportation, storage and post & 10 & 28 & 35 \\
I & Information technology (IT) & 6 & 11 & 30 \\
J & Finance & 10 & 26 & 56 \\
K & Real estate & 11 & 18 & 29 \\
\hline \hline
\end{tabular}


Table 3: Descriptive statistics of the CSSD and CSAD

This table summarizes the number of observations, mean, standard deviation, minimum and maximum value of the return dispersion measures. They are equallyand value-weighted measures constructed from individual stock returns as well as from stock portfolios. The table also reports the serial correlation for 1 , 3 , 5, 20 lags together with $t$-statistics of the Augmented Dickey-Fuller (ADF) test. The last column shows the correlation between CSSD/CSAD and the realized volatility of the CSI 300 index based on 5-minute return series. The sample period is from 1 August 2005 to 30 September 2017.

\begin{tabular}{|c|c|c|c|c|c|c|c|c|c|c|c|c|}
\hline \multirow[t]{2}{*}{ Code } & \multirow[t]{2}{*}{ Obs. } & \multirow[t]{2}{*}{ Mean } & \multirow[t]{2}{*}{ S.D. } & \multirow[t]{2}{*}{ Min } & \multirow[t]{2}{*}{$\operatorname{Max}$} & \multicolumn{5}{|c|}{ Serial correlation at lag } & \multirow{2}{*}{$\begin{array}{l}\mathrm{ADF} \\
t \text {-stat }\end{array}$} & \multirow[t]{2}{*}{ Corrrlation } \\
\hline & & & & & & 1 & 3 & 5 & 10 & 20 & & \\
\hline \multicolumn{13}{|c|}{ Panel A: Equally-weighted } \\
\hline CSSD & 3,038 & 0.021 & 0.007 & 0.003 & 0.066 & 0.740 & 0.661 & 0.647 & 0.622 & 0.534 & -6.159 & 0.194 \\
\hline CSAD & 3,038 & 0.015 & 0.006 & 0.000 & 0.057 & 0.725 & 0.647 & 0.635 & 0.607 & 0.528 & -7.200 & 0.200 \\
\hline \multicolumn{13}{|c|}{ Panel B: Value-weighted } \\
\hline CSSD & 3,038 & 0.019 & 0.007 & 0.002 & 0.070 & 0.753 & 0.701 & 0.669 & 0.626 & 0.550 & -7.265 & 0.182 \\
\hline CSAD & 3,038 & 0.014 & 0.006 & 0.000 & 0.062 & 0.737 & 0.690 & 0.651 & 0.599 & 0.530 & -8.588 & 0.172 \\
\hline \multicolumn{13}{|c|}{ Panel C: Portfolio CSSD } \\
\hline EW & 3,038 & 0.009 & 0.004 & 0.001 & 0.050 & 0.613 & 0.530 & 0.517 & 0.468 & 0.408 & -10.28 & 0.247 \\
\hline VW & 3,038 & 0.008 & 0.005 & 0.001 & 0.052 & 0.547 & 0.482 & 0.465 & 0.408 & 0.337 & -12.98 & 0.231 \\
\hline
\end{tabular}


Table 4: The in-sample volatility estimation

This table reports the in-sample volatility estimation of the GARCH and GARCH-X models (Panel A), the GJRGARCH and GJR-GARCH-X models (Panel B), and the HAR and HAR-X models (Panel C) for the CSI 300 index. The exogenous $\mathrm{X}$ variable $\theta$ is the CSSD/CSAD. The maximum likelihood (LL) and the adjusted $R^{2}$ are also reported. Standard errors are in parentheses. ${ }^{*} p<0.1 ;{ }^{* *} p<0.05 ;{ }^{* * *} p<0.01$.

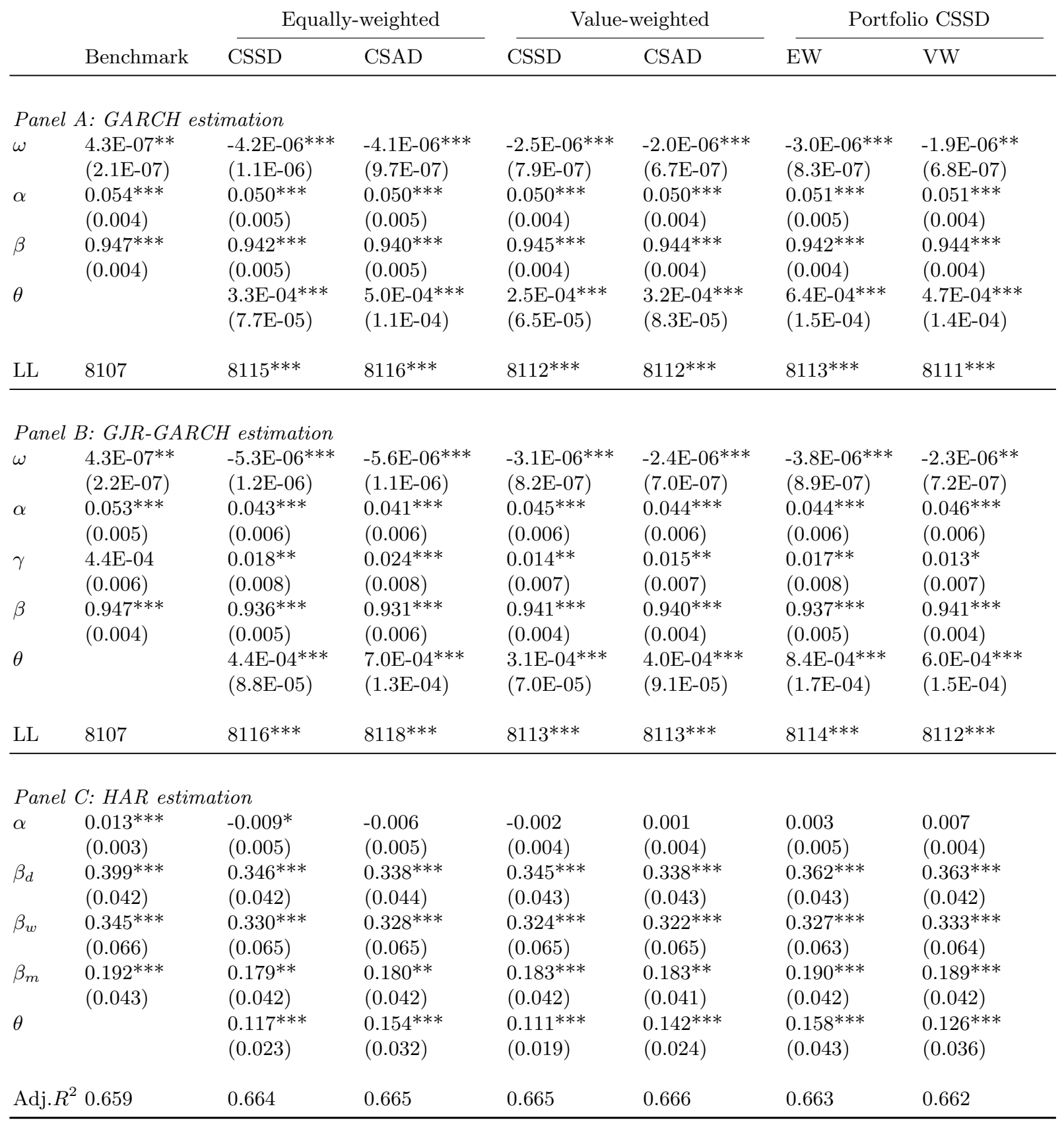


Table 5: Out-of-sample volatility forecasting performance: CSI 300 index

This table reports the out-of-sample forecasting performance between the GARCH, GJR-GARCH, and HAR models and the corresponding GARCH-X, GJRGARCH-X, and HAR-X models for the CSI 300 index. The root mean square error (RMSE), the mean absolute percentage error (MAPE), and the mean absolute error (MAE) are used. The $t$-statistic of the Diebold and Mariano (1995) (DM) test between forecasts from the benchmark and augmented models, and the adjusted $R^{2}$ of the Mincer-Zarnowitz (M-Z) regression are also reported. ${ }^{*} p<0.1 ;{ }^{* *} p<0.05 ;{ }^{* * *} p<0.01$.

\begin{tabular}{|c|c|c|c|c|c|c|c|}
\hline & \multirow[b]{2}{*}{ Benchmark } & \multicolumn{2}{|c|}{ Equally-weighted } & \multicolumn{2}{|c|}{ Value-weighted } & \multicolumn{2}{|c|}{ Portfolio CSSD } \\
\hline & & CSSD & CSAD & CSSD & CSAD & EW & VW \\
\hline \multicolumn{8}{|l|}{ Panel A: GARCH estimation } \\
\hline $\operatorname{RMSE}\left(\times 10^{2}\right)$ & 6.668 & 6.423 & 6.409 & 6.437 & 6.597 & 6.529 & 6.672 \\
\hline DM $t$-stat & & $6.159^{* * *}$ & $3.383^{* * *}$ & $4.375^{* * *}$ & 0.504 & $1.890^{*}$ & -0.026 \\
\hline MAPE (\%) & 143.5 & 144.7 & 139.3 & 148.4 & 142.5 & 146.9 & 145.9 \\
\hline DM $t$-stat & & -0.845 & $2.879^{* * *}$ & $-3.315^{* * *}$ & 0.617 & $-2.364^{* *}$ & $-1.667^{*}$ \\
\hline MAE $\left(\times 10^{2}\right)$ & 3.616 & 3.507 & 3.372 & 3.475 & 3.383 & 3.522 & 3.505 \\
\hline DM $t$-stat & & $4.212^{* * *}$ & $7.146^{* * *}$ & $4.355^{* * *}$ & $5.683^{* * *}$ & $2.840^{* * *}$ & $2.688^{* * *}$ \\
\hline Adj. $R^{2}$ of $\mathrm{M}-\mathrm{Z}$ regression & 0.336 & 0.369 & 0.363 & 0.364 & 0.320 & 0.348 & 0.313 \\
\hline \multicolumn{8}{|c|}{ Panel B: GJR-GARCH estimation } \\
\hline $\operatorname{RMSE}\left(\times 10^{2}\right)$ & 6.739 & 6.147 & 6.067 & 6.084 & 6.009 & 6.169 & 6.179 \\
\hline DM $t$-stat & & $6.693^{* * *}$ & $5.572^{* * *}$ & $5.107^{* * *}$ & $5.086^{* * *}$ & $4.826^{* * *}$ & $4.207^{* * *}$ \\
\hline MAPE (\%) & 148.2 & 142.8 & 139.5 & 147.9 & 143.9 & 150.0 & 150.5 \\
\hline DM $t$-stat & & $2.801^{* * *}$ & $4.225^{* * *}$ & 0.148 & $1.922^{*}$ & -0.861 & -1.104 \\
\hline $\operatorname{MAE}\left(\times 10^{2}\right)$ & 3.744 & 3.422 & 3.289 & 3.348 & 3.257 & 3.482 & 3.469 \\
\hline DM $t$-stat & & $7.788^{* * *}$ & $8.965^{* * *}$ & $7.660^{* * *}$ & $8.392 * * *$ & $5.237 * * *$ & $5.104^{* * *}$ \\
\hline Adj. $R^{2}$ of $\mathrm{M}-\mathrm{Z}$ regression & 0.344 & 0.428 & 0.435 & 0.435 & 0.448 & 0.430 & 0.427 \\
\hline
\end{tabular}




\begin{tabular}{|c|c|c|c|c|c|c|c|}
\hline \multicolumn{8}{|l|}{ Panel $C: H A R$ estimation } \\
\hline $\operatorname{RMSE}\left(\times 10^{2}\right)$ & 5.170 & 5.154 & 5.156 & 5.164 & 5.168 & 5.168 & 5.174 \\
\hline DM $t$-stat & & 0.754 & 0.488 & 0.269 & 0.074 & 0.088 & -0.173 \\
\hline MAPE (\%) & 49.25 & 47.82 & 47.64 & 48.52 & 48.23 & 48.98 & 48.52 \\
\hline DM $t$-stat & & $4.752^{* * *}$ & $5.330 * * *$ & $2.823^{* * *}$ & $4.238^{* * *}$ & 1.233 & $3.696^{* * *}$ \\
\hline $\operatorname{MAE}\left(\times 10^{2}\right)$ & 1.902 & 1.866 & 1.857 & 1.871 & 1.871 & 1.883 & 1.884 \\
\hline DM $t$-stat & & $4.550 * * *$ & $4.778 * * *$ & $3.929 * * *$ & $3.639 * * *$ & $2.634^{* * *}$ & $2.305^{* *}$ \\
\hline $\operatorname{Adj} . R^{2}$ of $\mathrm{M}-\mathrm{Z}$ regression & 0.555 & 0.560 & 0.561 & 0.558 & 0.557 & 0.556 & 0.555 \\
\hline \multicolumn{8}{|l|}{ 5-day ahead } \\
\hline $\operatorname{RMSE}\left(\times 10^{2}\right)$ & 3.949 & 3.851 & 3.836 & 3.897 & 3.919 & 3.917 & 3.949 \\
\hline DM $t$-stat & & $2.756^{* * *}$ & $2.424^{* * *}$ & 1.482 & 0.867 & 1.020 & -0.005 \\
\hline MAPE (\%) & 41.34 & 39.19 & 39.06 & 40.22 & 39.71 & 40.94 & 40.11 \\
\hline DM $t$-stat & & $4.809 * * *$ & $5.049 * * *$ & $2.992^{* * *}$ & $4.787^{* * *}$ & 1.283 & $4.735^{* * *}$ \\
\hline $\operatorname{MAE}\left(\times 10^{2}\right)$ & 1.573 & 1.507 & 1.492 & 1.515 & 1.516 & 1.546 & 1.545 \\
\hline DM $t$-stat & & $5.421^{* * *}$ & $5.461^{* * *}$ & $4.919 * * *$ & $4.787^{* * *}$ & $2.563^{* *}$ & $2.647^{* * *}$ \\
\hline Adj. $R^{2}$ of $\mathrm{M}-\mathrm{Z}$ regression & 0.583 & 0.602 & 0.606 & 0.592 & 0.588 & 0.588 & 0.582 \\
\hline \multicolumn{8}{|l|}{ 22-day ahead } \\
\hline $\operatorname{RMSE}\left(\times 10^{2}\right)$ & 3.592 & 3.190 & 3.099 & 3.295 & 3.346 & 3.338 & 3.424 \\
\hline DM $t$-stat & & $5.570^{* * *}$ & $5.429 * * *$ & $4.439 * * *$ & $3.831^{* * *}$ & $4.300^{* * *}$ & $2.888^{* * *}$ \\
\hline MAPE (\%) & 48.39 & 45.00 & 45.77 & 48.88 & 48.79 & 50.35 & 51.13 \\
\hline DM $t$-stat & & $4.316^{* * *}$ & $3.261^{* * *}$ & -0.738 & -0.625 & $-3.308^{* * *}$ & $-5.200 * * *$ \\
\hline $\operatorname{MAE}\left(\times 10^{2}\right)$ & 1.709 & 1.529 & 1.507 & 1.555 & 1.560 & 1.626 & 1.646 \\
\hline DM $t$-stat & & $9.080^{* * *}$ & $8.429^{* * *}$ & $7.938^{* * *}$ & $7.828 * * *$ & $4.600 * * *$ & $3.578^{* * *}$ \\
\hline $\operatorname{Adj} . R^{2}$ of $\mathrm{M}-\mathrm{Z}$ regression & 0.422 & 0.514 & 0.542 & 0.483 & 0.468 & 0.474 & 0.452 \\
\hline
\end{tabular}


Table 6: Out-of-sample volatility forecasting performance: Industry level, value-weighted

This table reports the out-of-sample forecasting performance between the GARCH, GJR-GARCH, and HAR models and corresponding augmented GARCH-X, GJR-GARCH-X, and HAR-X models at the industry level constructed via the value-weighting scheme from stocks in the industry. Realized volatility is calculated from 5-min value-weighted intraday component stock returns. The root mean square error (RMSE) is used. The $t$-statistic of the Diebold and Mariano (1995) (DM) test between forecasts from the benchmark and augmented models is also reported. ${ }^{*} p<0.1 ;{ }^{* *} p<0.05 ;{ }^{* * *} p<0.01$.

\begin{tabular}{|c|c|c|c|c|c|c|c|c|}
\hline & Mining & Manufacturing & Utilities & $\begin{array}{l}\text { Wholesale } \\
\text { and retail }\end{array}$ & $\begin{array}{l}\text { Transportation, } \\
\text { storage and post }\end{array}$ & IT & Finance & Real estate \\
\hline \multicolumn{9}{|c|}{ Panel A: GARCH estimation } \\
\hline Benchmark & 14.05 & 17.37 & 17.75 & 18.89 & 20.90 & 21.82 & 13.53 & 18.40 \\
\hline CSSD EW & 14.12 & 17.54 & 18.04 & 19.07 & 20.89 & 22.63 & 13.21 & 18.78 \\
\hline DM $t$-stat & -0.864 & $-3.599^{* * *}$ & $-3.460^{* * *}$ & -0.787 & 0.609 & $-4.014^{* * *}$ & $5.697^{* * *}$ & $-2.030^{* *}$ \\
\hline CSAD EW & 14.26 & 17.64 & 18.27 & 19.30 & 20.93 & 22.68 & 13.26 & 19.03 \\
\hline DM $t$-stat & $-1.991^{* *}$ & $-3.715^{* * *}$ & $-2.499 * *$ & -1.323 & -1.066 & $-4.131^{* * *}$ & $4.323^{* * *}$ & $-2.595^{* * *}$ \\
\hline CSSD VW & 14.27 & 17.63 & 18.10 & 19.04 & 20.92 & 22.62 & 13.25 & 18.86 \\
\hline DM $t$-stat & $-2.009^{* *}$ & $-4.229^{* * *}$ & $-3.560^{* * *}$ & -0.669 & -0.995 & $-3.915^{* * *}$ & $4.628^{* * *}$ & $-2.124^{* *}$ \\
\hline CSAD VW & 14.42 & 17.70 & 18.31 & 19.10 & 20.95 & 22.67 & 13.36 & 18.81 \\
\hline DM $t$-stat & $-2.260^{* *}$ & $-3.860^{* * *}$ & $-2.700^{* * *}$ & -0.879 & $-2.691^{* * *}$ & $-4.050 * * *$ & $2.209^{* *}$ & $-1.895^{*}$ \\
\hline Port CSSD EW & 14.27 & 17.55 & 18.27 & 19.21 & 20.89 & 22.56 & 13.19 & 18.80 \\
\hline DM $t$-stat & $-1.893^{*}$ & $-2.620^{* * *}$ & $-2.536^{* *}$ & -1.013 & 0.372 & $-3.313^{* * *}$ & $5.315^{* * *}$ & $-1.702^{*}$ \\
\hline Port CSSD VW & V 14.44 & 17.63 & 18.30 & 19.14 & 20.93 & 22.47 & 13.28 & 18.64 \\
\hline DM $t$-stat & $-2.267^{* *}$ & $-2.421^{* *}$ & $-2.609 * * *$ & -0.887 & -1.534 & $-3.788^{* * *}$ & $3.731^{* * *}$ & -1.141 \\
\hline \multicolumn{9}{|c|}{ Panel B: GJR-GARCH estimation } \\
\hline Benchmark & 14.29 & 16.94 & 18.06 & 18.78 & 21.26 & 22.20 & 13.56 & 18.52 \\
\hline CSSD EW & 14.32 & 16.91 & 18.32 & 18.28 & 21.24 & 22.58 & 13.19 & 18.67 \\
\hline DM $t$-stat & -0.535 & 0.208 & $-3.387^{* * *}$ & 1.429 & 0.356 & $-3.490^{* * *}$ & $4.734^{* * *}$ & -1.032 \\
\hline CSAD EW & 14.42 & 17.02 & 18.52 & 18.35 & 21.33 & 22.67 & 13.23 & 18.96 \\
\hline DM $t$-stat & $-2.122^{* *}$ & -0.596 & $-2.467^{* *}$ & 1.229 & $-1.800^{*}$ & $-2.814^{* * *}$ & $3.859^{* * *}$ & $-1.953^{*}$ \\
\hline CSSD VW & 14.43 & 17.04 & 18.33 & 18.28 & 21.30 & 22.57 & 13.22 & 18.63 \\
\hline DM $t$-stat & $-2.167^{* *}$ & -0.723 & $-3.303^{* * *}$ & 1.399 & -1.048 & $-1.951^{*}$ & $3.653^{* * *}$ & -0.679 \\
\hline CSAD VW & 14.38 & 17.13 & 18.49 & 18.27 & 21.41 & 22.59 & 13.35 & 18.71 \\
\hline DM $t$-stat & -0.543 & -1.299 & $-2.568^{* *}$ & 1.442 & $-5.075^{* * *}$ & $-2.145^{* *}$ & $2.053^{* *}$ & -0.962 \\
\hline Port CSSD EW & 14.40 & 16.84 & 18.39 & 18.24 & 21.28 & 22.59 & 13.16 & 18.59 \\
\hline DM $t$-stat & $-1.670^{*}$ & 0.725 & $-2.076^{* *}$ & 1.608 & -0.399 & $-2.001^{* *}$ & $4.508^{* * *}$ & -0.307 \\
\hline Port CSSD VW & 14.47 & 16.96 & 18.39 & 18.21 & 21.31 & 22.50 & 13.25 & 18.53 \\
\hline DM $t$-stat & -1.265 & -0.130 & $-2.111^{* *}$ & $1.730^{*}$ & -1.242 & -1.636 & $3.387^{* * *}$ & -0.071 \\
\hline
\end{tabular}




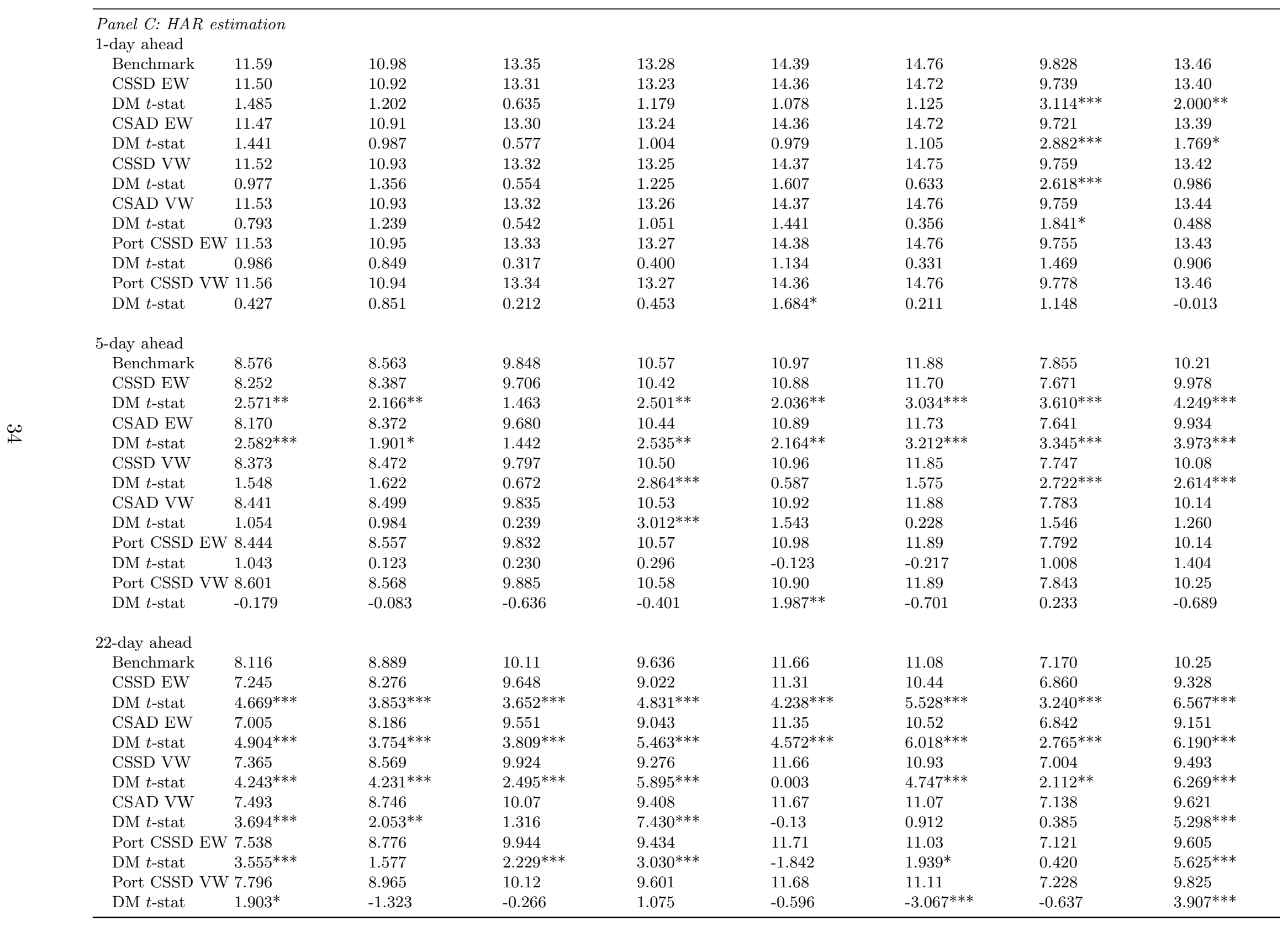


Table 7: Economic value of volatility forecasts: CSI 300 index

This table reports portfolio excess return (Ret), the Sharpe ratio (SR), and the manipulation proof performance measure (MPPM) of portfolios under a mean-variance utility framework with $\Gamma$ as investor risk aversion level. The bold font highlights the best economic performance among the three forecasting models.

\begin{tabular}{ccc}
\multicolumn{3}{c}{$\Gamma=6$} \\
\hline Ret & SR & MPPM
\end{tabular}

Panel A: Equally-weighted GARCH

$\mathrm{GARCH}+\mathrm{CSSD}$

GARCH+CSAD

GJR-GARCH

GJR-GARCH+CSSD

GJR-GARCH+CSAD

HAR

$\mathrm{HAR}+\mathrm{CSSD}$

$\mathrm{HAR}+\mathrm{CSAD}$

Panel B: Value-weighted

GARCH

GARCH+CSSD

$\mathrm{GARCH}+\mathrm{CSAD}$

GJR-GARCH

GJR-GARCH+CSSD

GJR-GARCH+CSAD

HAR

$\mathrm{HAR}+\mathrm{CSSD}$

$\mathrm{HAR}+\mathrm{CSAD}$

Panel C: Portfolio CSSD

GARCH

GARCH+CSSD EW

GARCH+CSSD VW

GJR-GARCH

GJR-GARCH+CSSD EW

GJR-GARCH+CSSD VW

HAR

$\mathrm{HAR}+\mathrm{CSSD}$ EW

HAR+CSSD VW

\begin{tabular}{ccccccc}
$\mathbf{- 0 . 4 5 6}$ & -0.045 & 0.037 & $\mathbf{- 0 . 6 2 8}$ & -0.086 & 0.031 \\
-0.466 & $\mathbf{- 0 . 0 4 3}$ & 0.041 & -0.693 & $\mathbf{- 0 . 0 8 5}$ & 0.038 \\
-0.682 & -0.063 & $\mathbf{0 . 0 4 3}$ & -0.895 & -0.109 & $\mathbf{0 . 0 4 1}$ \\
& & & & & \\
-0.144 & -0.014 & 0.032 & $\mathbf{- 0 . 4 2 4}$ & $\mathbf{- 0 . 0 5 9}$ & 0.028 \\
$\mathbf{- 0 . 0 4 8}$ & $\mathbf{- 0 . 0 0 4}$ & 0.037 & -0.634 & -0.077 & 0.039 \\
-0.387 & -0.036 & $\mathbf{0 . 0 4 0}$ & -0.953 & -0.115 & $\mathbf{0 . 0 4 2}$ \\
& & & & & \\
-0.156 & -0.011 & 0.068 & $\mathbf{- 0 . 0 7 7}$ & $\mathbf{- 0 . 0 0 7}$ & 0.058 \\
$\mathbf{- 0 . 0 1 8}$ & $\mathbf{- 0 . 0 0 1}$ & 0.070 & -0.086 & -0.007 & 0.063 \\
-0.086 & -0.006 & $\mathbf{0 . 0 7 1}$ & -0.177 & -0.015 & $\mathbf{0 . 0 6 5}$ \\
\hline
\end{tabular}

\begin{tabular}{ccccccc}
-0.456 & -0.045 & 0.037 & $\mathbf{- 0 . 6 2 8}$ & $\mathbf{- 0 . 0 8 6}$ & 0.031 \\
-0.341 & -0.031 & 0.041 & -1.121 & -0.136 & 0.043 \\
$\mathbf{- 0 . 3 2 1}$ & $\mathbf{- 0 . 0 2 9}$ & $\mathbf{0 . 0 4 2}$ & -1.057 & -0.126 & $\mathbf{0 . 0 4 4}$ \\
& & & & & \\
-0.144 & -0.014 & 0.032 & $\mathbf{- 0 . 4 2 4}$ & $\mathbf{- 0 . 0 5 9}$ & 0.028 \\
0.055 & 0.005 & $\mathbf{0 . 0 3 7}$ & -1.015 & -0.121 & 0.043 \\
$\mathbf{0 . 2 1 4}$ & $\mathbf{0 . 0 1 9}$ & 0.037 & -0.941 & -0.110 & $\mathbf{0 . 0 4 4}$ \\
& & & & & \\
$\mathbf{- 0 . 1 5 6}$ & -0.011 & 0.068 & $\mathbf{- 0 . 0 7 7}$ & $\mathbf{- 0 . 0 0 7}$ & 0.058 \\
$\mathbf{- 0 . 1 6 1}$ & $\mathbf{- 0 . 0 1 1}$ & 0.073 & -0.209 & -0.018 & 0.065 \\
-0.222 & -0.015 & $\mathbf{0 . 0 7 4}$ & -0.268 & -0.023 & $\mathbf{0 . 0 6 6}$ \\
\hline
\end{tabular}

\begin{tabular}{cccccc}
$\mathbf{- 0 . 4 5 6}$ & $\mathbf{- 0 . 0 4 5}$ & 0.037 & $\mathbf{- 0 . 6 2 8}$ & $\mathbf{- 0 . 0 8 6}$ & 0.031 \\
-0.848 & -0.080 & $\mathbf{0 . 0 4 3}$ & -1.098 & -0.136 & 0.042 \\
-0.734 & -0.068 & 0.043 & -1.208 & -0.149 & $\mathbf{0 . 0 4 3}$ \\
& & & & & \\
$\mathbf{- 0 . 1 4 4}$ & $\mathbf{- 0 . 0 1 4}$ & 0.032 & $\mathbf{- 0 . 4 2 4}$ & $\mathbf{- 0 . 0 5 9}$ & 0.028 \\
-0.524 & -0.050 & $\mathbf{0 . 0 3 9}$ & -1.234 & -0.154 & 0.043 \\
-0.338 & -0.032 & 0.037 & -1.243 & -0.154 & $\mathbf{0 . 0 4 3}$ \\
& & & & & \\
$\mathbf{- 0 . 1 5 6}$ & $\mathbf{- 0 . 0 1 1}$ & 0.068 & -0.077 & $\mathbf{- 0 . 0 0 7}$ & 0.058 \\
-0.310 & -0.021 & 0.071 & $\mathbf{- 0 . 3 3 8}$ & -0.030 & 0.064 \\
-0.404 & -0.027 & $\mathbf{0 . 0 7 3}$ & -0.365 & -0.032 & $\mathbf{0 . 0 6 5}$ \\
\hline
\end{tabular}


Table 8: Robustness: Volatility forecasting with realized median as true volatility proxy, CSI 300 index

This table reports the out-of-sample forecasting performance between the GARCH, GJR-GARCH, and HAR models and the corresponding GARCH-X, GJRGARCH-X, and HAR-X models using the realized median as the volatility proxy for the CSI 300 index. The root mean square error (RMSE), the mean absolute percentage error (MAPE), and the mean absolute error (MAE) are used. The $t$-statistic of the Diebold and Mariano (1995) (DM) test between forecasts from the benchmark and augmented models, and the adjusted $R^{2}$ of the Mincer-Zarnowitz (M-Z) regression are also reported. ${ }^{*} p<0.1 ;{ }^{* *} p<0.05 ;{ }^{* * *} p<0.01$.

\begin{tabular}{|c|c|c|c|c|c|c|c|}
\hline & \multirow[b]{2}{*}{ Benchmark } & \multicolumn{2}{|c|}{ Equally-weighted } & \multicolumn{2}{|c|}{ Value-weighted } & \multicolumn{2}{|c|}{ Portfolio CSSD } \\
\hline & & CSSD & CSAD & CSSD & CSAD & EW & VW \\
\hline \multicolumn{8}{|l|}{ Panel A: GARCH estimation } \\
\hline $\operatorname{RMSE}\left(\times 10^{2}\right)$ & 6.755 & 6.448 & 6.398 & 6.443 & 6.566 & 6.532 & 6.655 \\
\hline DM $t$-stat & & $6.958^{* * *}$ & $4.397^{* * *}$ & $5.306^{* * *}$ & 1.143 & $2.781^{* * *}$ & 0.494 \\
\hline MAPE (\%) & 184.9 & 186.0 & 179.5 & 190.6 & 183.3 & 188.8 & 187.3 \\
\hline DM $t$-stat & & -0.730 & $3.015^{* * *}$ & $-3.270^{* * *}$ & 0.815 & $-2.247^{* *}$ & -1.415 \\
\hline MAE $\left(\times 10^{2}\right)$ & 3.868 & 3.726 & 3.583 & 3.687 & 3.586 & 3.747 & 3.715 \\
\hline DM $t$-stat & & $4.360^{* * *}$ & $7.415^{* * *}$ & $4.677^{* * *}$ & $6.031^{* * *}$ & $2.782^{* * *}$ & $2.936^{* * *}$ \\
\hline Adj. $R^{2}$ of $\mathrm{M}-\mathrm{Z}$ regression & 0.321 & 0.345 & 0.340 & 0.341 & 0.300 & 0.327 & 0.293 \\
\hline \multicolumn{8}{|c|}{ Panel B: GJR-GARCH estimation } \\
\hline $\operatorname{RMSE}\left(\times 10^{2}\right)$ & 6.879 & 6.263 & 6.150 & 6.178 & 6.083 & 6.278 & 6.274 \\
\hline DM $t$-stat & & $7.249^{* * *}$ & $5.998^{* * *}$ & $5.524^{* * *}$ & $5.489^{* * *}$ & $5.081^{* * *}$ & $4.437^{* * *}$ \\
\hline MAPE (\%) & 190.9 & 184.4 & 180.5 & 190.9 & 185.9 & 193.2 & 193.6 \\
\hline DM $t$-stat & & $2.914^{* * *}$ & $4.306^{* * *}$ & 0.083 & $1.985^{* *}$ & -0.835 & -1.012 \\
\hline $\operatorname{MAE}\left(\times 10^{2}\right)$ & 4.004 & 3.645 & 3.512 & 3.576 & 3.476 & 3.717 & 3.694 \\
\hline DM $t$-stat & & $8.170^{* * *}$ & $9.141^{* * *}$ & $7.778^{* * *}$ & $8.467^{* * *}$ & $5.241^{* * *}$ & $5.150^{* * *}$ \\
\hline $\mathrm{Adj} . R^{2}$ of $\mathrm{M}-\mathrm{Z}$ regression & 0.321 & 0.392 & 0.398 & 0.397 & 0.411 & 0.393 & 0.393 \\
\hline
\end{tabular}




\begin{tabular}{|c|c|c|c|c|c|c|c|}
\hline \multicolumn{8}{|l|}{ Panel C: HAR estimation } \\
\hline \multicolumn{8}{|l|}{ 1-day ahead } \\
\hline $\operatorname{RMSE}\left(\times 10^{2}\right)$ & 5.028 & 5.013 & 5.014 & 5.022 & 5.025 & 5.027 & 5.032 \\
\hline DM $t$-stat & & 0.682 & 0.462 & 0.264 & 0.111 & 0.053 & -0.174 \\
\hline MAPE $(\%)$ & 51.34 & 49.51 & 49.25 & 50.24 & 49.93 & 50.77 & 50.27 \\
\hline DM $t$-stat & & $5.615^{* * *}$ & $6.326^{* * *}$ & $3.981^{* * *}$ & $5.505^{* * *}$ & $2.427^{* *}$ & $5.101^{* * *}$ \\
\hline $\operatorname{MAE}\left(\times 10^{2}\right)$ & 1.754 & 1.720 & 1.711 & 1.721 & 1.721 & 1.736 & 1.736 \\
\hline DM $t$-stat & & $4.857^{* * *}$ & $4.947^{* * *}$ & $4.597^{* * *}$ & $4.408^{* * *}$ & $2.849^{* * *}$ & $2.579^{* *}$ \\
\hline $\operatorname{Adj} . R^{2}$ of $\mathrm{M}-\mathrm{Z}$ regression & 0.550 & 0.555 & 0.556 & 0.554 & 0.553 & 0.552 & 0.550 \\
\hline \multicolumn{8}{|l|}{ 5-day ahead } \\
\hline $\operatorname{RMSE}\left(\times 10^{2}\right)$ & 3.837 & 3.737 & 3.717 & 3.781 & 3.802 & 3.802 & 3.835 \\
\hline DM $t$-stat & & $2.490^{* *}$ & $2.252^{* *}$ & 1.410 & 0.919 & 0.986 & 0.057 \\
\hline MAPE (\%) & 43.27 & 40.49 & 40.25 & 41.54 & 41.04 & 42.38 & 41.51 \\
\hline DM $t$-stat & & $5.716^{* * *}$ & $6.089^{* * *}$ & $4.464^{* * *}$ & $6.357^{* * *}$ & $2.766^{* * *}$ & $6.571^{* * *}$ \\
\hline $\operatorname{MAE}\left(\times 10^{2}\right)$ & 1.473 & 1.404 & 1.390 & 1.410 & 1.411 & 1.441 & 1.440 \\
\hline DM $t$-stat & & $5.927^{* * *}$ & $5.927 * * *$ & $5.731^{* * *}$ & $5.702^{* * *}$ & $3.203^{* * *}$ & $3.330 * * *$ \\
\hline $\operatorname{Adj} . R^{2}$ of $\mathrm{M}-\mathrm{Z}$ regression & 0.572 & 0.591 & 0.596 & 0.581 & 0.577 & 0.577 & 0.571 \\
\hline \multicolumn{8}{|l|}{ 22-day ahead } \\
\hline $\operatorname{RMSE}\left(\times 10^{2}\right)$ & 3.435 & 3.059 & 2.966 & 3.160 & 3.213 & 3.199 & 3.288 \\
\hline DM $t$-stat & & $5.176^{* * *}$ & $5.088^{* * *}$ & $4.073^{* * *}$ & $3.501^{* * *}$ & $3.911^{* * *}$ & $2.502^{* *}$ \\
\hline MAPE (\%) & 51.20 & 47.07 & 47.81 & 51.03 & 51.04 & 52.59 & 53.59 \\
\hline DM $t$-stat & & $4.880^{* * *}$ & $3.891^{* * *}$ & 0.249 & 0.247 & $-2.231^{* *}$ & $-4.585^{* * *}$ \\
\hline $\operatorname{MAE}\left(\times 10^{2}\right)$ & 1.589 & 1.420 & 1.398 & 1.448 & 1.459 & 1.511 & 1.538 \\
\hline DM $t$-stat & & $9.053^{* * *}$ & $8.414^{* * *}$ & $7.899 * * *$ & $7.611^{* * *}$ & $4.622^{* * *}$ & $3.191^{* * *}$ \\
\hline $\operatorname{Adj} . R^{2}$ of $\mathrm{M}-\mathrm{Z}$ regression & 0.417 & 0.507 & 0.537 & 0.475 & 0.460 & 0.467 & 0.443 \\
\hline
\end{tabular}


Table 9: Robustness: Volatility forecasting with realized median as true volatility proxy, industry level, value-weighted

This table reports the out-of-sample forecasting performance between the GARCH, GJR-GARCH, and HAR models and corresponding augmented GARCH-X, GJR-GARCH-X, and HAR-X models at the industry level constructed via the value-weighting scheme from stocks in the industry. Realized median is calculated from 5-min value-weighted intraday component stock returns. The root mean square error (RMSE) is used. The $t$-statistic of the Diebold and Mariano (1995) (DM) test between forecasts from the benchmark and augmented models is also reported. ${ }^{*} p<0.1 ;{ }^{* *} p<0.05 ;{ }^{* * *} p<0.01$.

\begin{tabular}{|c|c|c|c|c|c|c|c|}
\hline Mining & Manufacturing & Utilities & $\begin{array}{l}\text { Wholesale } \\
\text { and retail }\end{array}$ & $\begin{array}{l}\text { Transportation, } \\
\text { storage and post }\end{array}$ & IT & Finance & Real estate \\
\hline \multicolumn{8}{|c|}{ Panel A: GARCH estimation } \\
\hline 12.51 & 14.88 & 15.88 & 17.32 & 17.84 & 18.29 & 12.35 & 15.02 \\
\hline 12.54 & 14.99 & 16.07 & 17.29 & 17.78 & 18.90 & 12.02 & 15.38 \\
\hline-0.383 & $-2.188^{* *}$ & $-2.254^{* *}$ & 0.101 & $2.498^{* *}$ & $-2.967 * * *$ & $5.872^{* * *}$ & $-1.989^{* *}$ \\
\hline 12.65 & 15.07 & 16.23 & 17.48 & 17.81 & 18.95 & 12.06 & 15.48 \\
\hline-1.378 & $-2.436^{* *}$ & $-2.087 * *$ & -0.488 & 0.959 & $-3.134^{* * *}$ & $4.602^{* * *}$ & $-2.277^{* *}$ \\
\hline 12.65 & 15.07 & 16.11 & 17.26 & 17.82 & 18.88 & 12.05 & 15.37 \\
\hline-1.328 & $-2.881 * * *$ & $-2.299 * *$ & 0.248 & 0.973 & $-2.856^{* * *}$ & $4.928^{* * *}$ & $-1.914^{*}$ \\
\hline 12.76 & 15.12 & 16.26 & 17.32 & 17.86 & 18.94 & 12.18 & 15.32 \\
\hline-1.613 & $-2.667 * * *$ & $-2.289 * *$ & 0.007 & -0.808 & $-3.043^{* * *}$ & $2.402^{* *}$ & $-1.664^{*}$ \\
\hline 12.69 & 14.99 & 16.22 & 17.42 & 17.79 & 18.83 & 12.02 & 15.37 \\
\hline-1.637 & -1.534 & $-2.086^{* *}$ & -0.302 & $2.017^{* *}$ & $-2.450^{* *}$ & $5.416^{* * *}$ & $-1.812^{*}$ \\
\hline 12.84 & 15.06 & 16.25 & 17.36 & 17.84 & 18.76 & 12.11 & 15.25 \\
\hline$-1.960 * *$ & -1.542 & $-2.125^{* *}$ & -0.141 & 0.293 & $-2.750^{* * *}$ & $3.736^{* * *}$ & -1.338 \\
\hline \multicolumn{8}{|c|}{ Panel B: GJR-GARCH estimation } \\
\hline 12.72 & 14.49 & 16.16 & 17.23 & 18.16 & 18.64 & 12.39 & 15.17 \\
\hline 12.72 & 14.40 & 16.35 & 16.37 & 18.12 & 18.88 & 12.02 & 15.33 \\
\hline-0.070 & 0.788 & $-2.499^{* *}$ & $2.212^{* *}$ & 1.148 & $-2.167^{* *}$ & $4.612^{* * *}$ & -1.054 \\
\hline 12.80 & 14.48 & 16.49 & 16.43 & 18.19 & 18.95 & 12.06 & 15.46 \\
\hline-1.383 & 0.074 & $-2.182^{* *}$ & $2.064^{* *}$ & -0.735 & $-1.867^{*}$ & $3.896^{* * *}$ & -1.583 \\
\hline 12.81 & 14.50 & 16.35 & 16.37 & 18.17 & 18.87 & 12.06 & 15.27 \\
\hline-1.494 & -0.096 & $-2.245^{* *}$ & $2.186^{* *}$ & -0.293 & -1.212 & $3.746^{* * *}$ & -0.641 \\
\hline 12.76 & 14.59 & 16.45 & 16.36 & 18.28 & 18.89 & 12.19 & 15.26 \\
\hline-0.305 & -0.625 & $-2.166^{* *}$ & $2.237^{* *}$ & -3.832 & -1.385 & $2.052^{* *}$ & -0.535 \\
\hline 12.80 & 14.33 & 16.36 & 16.36 & 18.14 & 18.86 & 12.01 & 15.21 \\
\hline-1.344 & 1.208 & -1.561 & $2.315^{* *}$ & 0.421 & -1.166 & $4.368^{* * *}$ & -0.242 \\
\hline 12.85 & 14.43 & 16.35 & 16.34 & 18.20 & 18.82 & 12.11 & 15.20 \\
\hline-1.114 & 0.360 & -1.473 & $2.425^{* *}$ & -0.812 & -1.016 & $3.177^{* * *}$ & -0.191 \\
\hline
\end{tabular}




\begin{tabular}{|c|c|c|c|c|c|c|c|}
\hline \multicolumn{8}{|l|}{ Panel $C: H A R$ estimation } \\
\hline \multicolumn{8}{|l|}{ 1-day ahead } \\
\hline Benchmark & 10.12 & 12.12 & 13.03 & 12.80 & 13.17 & 9.079 & 11.20 \\
\hline CSSD EW & 10.06 & 12.07 & 12.98 & 12.76 & 13.12 & 9.003 & 11.15 \\
\hline DM $t$-stat & 1.034 & 0.632 & 1.138 & 1.036 & 1.007 & $2.776^{* * *}$ & $2.088^{* *}$ \\
\hline CSAD EW & 10.06 & 12.06 & 12.99 & 12.76 & 13.13 & 8.993 & 11.14 \\
\hline DM $t$-stat & 0.835 & 0.569 & 0.975 & 0.976 & 0.964 & $2.597 * * *$ & $1.893^{*}$ \\
\hline CSSD VW & 10.06 & 12.08 & 13.00 & 12.77 & 13.15 & 9.021 & 11.17 \\
\hline DM $t$-stat & 1.242 & 0.522 & 1.261 & $2.244^{* *}$ & 0.686 & $2.347^{* *}$ & 0.989 \\
\hline CSAD VW & 10.07 & 12.09 & 13.01 & 12.77 & 13.16 & 9.026 & 11.18 \\
\hline DM $t$-stat & 1.184 & 0.445 & 1.100 & 1.639 & 0.485 & $1.736^{*}$ & 0.438 \\
\hline Port CSSD EW 10.98 & 10.09 & 12.10 & 13.02 & 12.78 & 13.16 & 9.021 & 11.17 \\
\hline DM $t$-stat $\quad 0.887$ & 0.690 & 0.302 & 0.525 & 1.382 & 0.369 & 1.468 & 0.883 \\
\hline Port CSSD VW 11.01 & 10.09 & 12.11 & 13.02 & 12.78 & 13.16 & 9.043 & 11.20 \\
\hline DM $t$-stat & 0.733 & 0.138 & 0.536 & 1.593 & 0.221 & 1.097 & -0.047 \\
\hline \multicolumn{8}{|l|}{ 5-day ahead } \\
\hline Benchmark & 7.759 & 8.939 & 10.14 & 9.665 & 10.27 & 7.120 & 8.612 \\
\hline CSSD EW & 7.569 & 8.781 & 9.960 & 9.533 & 10.09 & 6.977 & 8.411 \\
\hline DM $t$-stat & $2.005^{* *}$ & 1.268 & $2.444^{* *}$ & $2.080^{* *}$ & $2.915^{* * *}$ & $3.205^{* * *}$ & $4.348^{* * *}$ \\
\hline CSAD EW & 7.551 & 8.754 & 9.979 & 9.540 & 10.12 & 6.962 & 8.373 \\
\hline DM $t$-stat & $1.751^{*}$ & 1.226 & $2.473^{* *}$ & $2.243^{* *}$ & $3.053^{* * *}$ & $2.977^{* * *}$ & $4.125^{* * *}$ \\
\hline CSSD VW & 7.647 & 8.868 & 10.06 & 9.630 & 10.23 & 7.038 & 8.490 \\
\hline DM $t$-stat & $1.963^{* *}$ & 0.663 & $2.733^{* * *}$ & 1.579 & $1.707^{* *}$ & $2.261^{* *}$ & $2.533^{* *}$ \\
\hline CSAD VW & 7.681 & 8.909 & 10.09 & 9.636 & 10.26 & 7.068 & 8.546 \\
\hline DM $t$-stat & 1.476 & 0.340 & $3.056^{* * *}$ & 1.095 & 0.648 & 1.320 & 1.209 \\
\hline Port CSSD EW 7.419 & 7.734 & 8.900 & 10.11 & 9.664 & 10.27 & 7.073 & 8.549 \\
\hline DM $t$-stat & 0.488 & 0.399 & 0.825 & 0.052 & 0.131 & 0.905 & 1.411 \\
\hline Port CSSD VW 7.555 & 7.764 & 8.966 & 10.14 & 9.643 & 10.28 & 7.116 & 8.647 \\
\hline DM $t$-stat $\quad-0.415$ & -0.104 & -0.302 & 0.024 & 0.929 & -0.881 & 0.110 & -0.602 \\
\hline \multicolumn{8}{|l|}{ 22-day ahead } \\
\hline Benchmark & 7.903 & 9.217 & 8.802 & 10.23 & 9.339 & 6.485 & 8.846 \\
\hline CSSD EW & 7.267 & 8.730 & 8.145 & 9.748 & 8.741 & 6.244 & 8.067 \\
\hline DM $t$-stat & $3.852^{* * *}$ & $3.423^{* * *}$ & $4.666^{* * *}$ & $4.218^{* * *}$ & $5.569^{* * *}$ & $2.813^{* * *}$ & $6.276^{* * *}$ \\
\hline CSAD EW & 7.169 & 8.628 & 8.162 & 9.791 & 8.825 & 6.246 & 7.909 \\
\hline DM $t$-stat & $3.775^{* * *}$ & $3.544^{* * *}$ & $5.173^{* * *}$ & $4.555^{* * *}$ & $6.013^{* * *}$ & $2.348^{* *}$ & $5.978 * * *$ \\
\hline CSSD VW & 7.508 & 8.967 & 8.412 & 10.12 & 9.175 & 6.361 & 8.200 \\
\hline DM $t$-stat & $4.155^{* * *}$ & $2.365^{* * *}$ & $5.492^{* * *}$ & $3.310^{* * *}$ & $4.986^{* * *}$ & $1.719^{*}$ & $5.951^{* * *}$ \\
\hline CSAD VW & 7.676 & 9.092 & 8.556 & 10.23 & 9.308 & 6.462 & 8.300 \\
\hline DM $t$-stat & $4.466^{* * *}$ & $1.891^{*}$ & $7.003^{* * *}$ & -0.054 & $2.215^{* *}$ & 0.309 & $5.028 * * *$ \\
\hline Port CSSD EW 6.641 & 7.712 & 8.983 & 8.549 & 10.20 & 9.277 & 6.456 & 8.286 \\
\hline DM $t$-stat $\quad 3.814^{* * *}$ & $2.076^{* * *}$ & $2.324^{* * *}$ & $3.413^{* * *}$ & 1.042 & $2.207^{* *}$ & 0.280 & $5.404^{* * *}$ \\
\hline Port CSSD VW 6.848 & 7.907 & 9.158 & 8.727 & 10.27 & 9.370 & 6.540 & 8.476 \\
\hline DM $t$-stat $\quad 2.170$ & -0.088 & 0.828 & 2.032 & -1.396 & $-3.192^{* * *}$ & -0.706 & $3.696^{* * *}$ \\
\hline
\end{tabular}


Table 10: Robustness: Subsample volatility forecasting performance: CSI 300 index from 2005 to 2011

This table reports the subsample forecasting performance between the GARCH, GJR-GARCH, and HAR models and the corresponding GARCH-X, GJRGARCH-X, and HAR-X models for the CSI 300 index from August 2005 to December 2011. The root mean square error (RMSE), the mean absolute percentage error (MAPE), and the mean absolute error (MAE) are used. The $t$-statistic of the Diebold and Mariano (1995) (DM) test between forecasts from the benchmark and augmented models, and the adjusted $R^{2}$ of the Mincer-Zarnowitz (M-Z) regression are also reported. ${ }^{*} p<0.1 ;{ }^{* *} p<0.05 ;{ }^{* * *} p<0.01$.

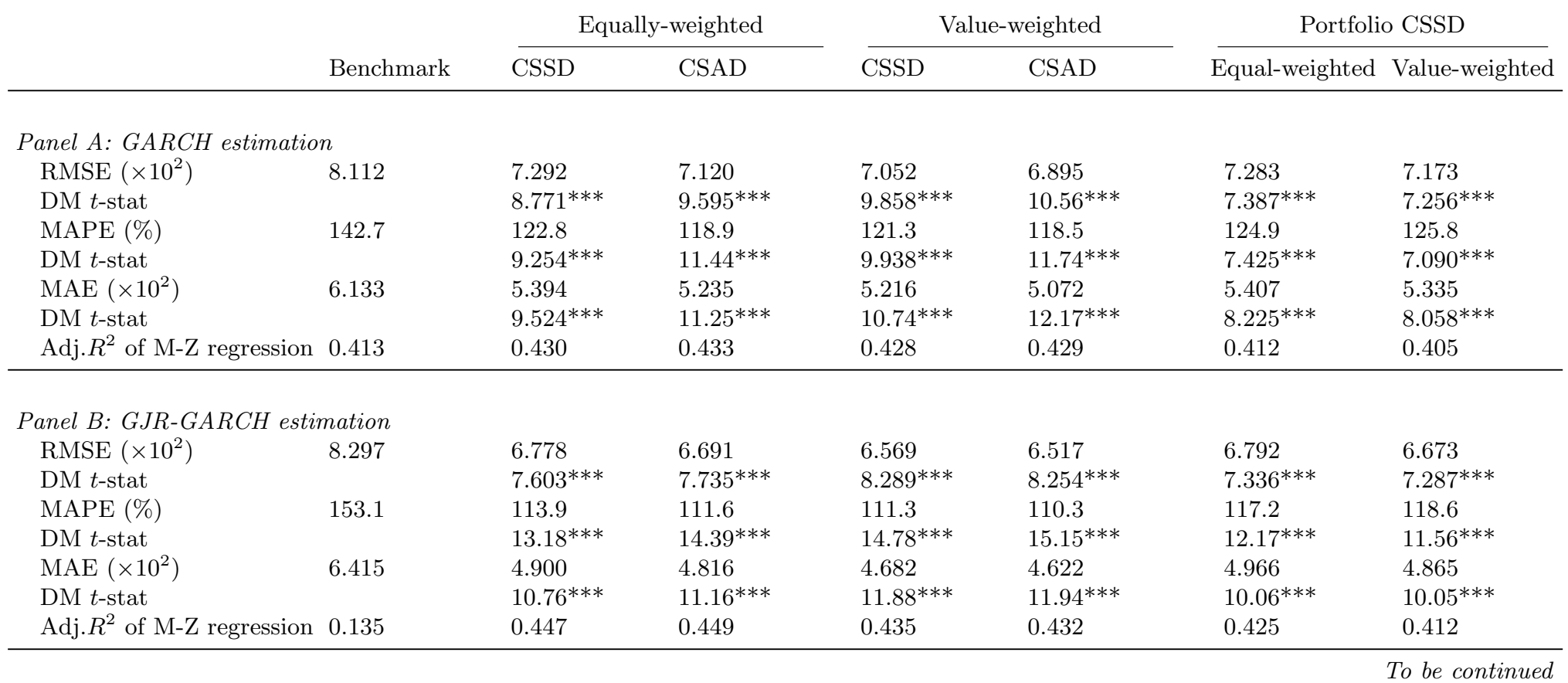




\begin{tabular}{|c|c|c|c|c|c|c|c|}
\hline $\begin{array}{l}\text { Panel C: HAR estimation } \\
\text { 1-day ahead }\end{array}$ & \multicolumn{3}{|c|}{ Panel $C: H A R$ estimation } & & & & \\
\hline $\operatorname{RMSE}\left(\times 10^{2}\right)$ & 5.193 & 5.183 & 5.185 & 5.197 & 5.202 & 5.197 & 5.211 \\
\hline DM $t$-stat & & 0.693 & 0.451 & -0.151 & -0.339 & -0.166 & -0.666 \\
\hline MAPE $(\%)$ & 48.53 & 44.86 & 44.54 & 44.28 & 44.25 & 46.06 & 45.98 \\
\hline DM $t$-stat & & $9.343^{* * *}$ & $9.831^{* * *}$ & $11.58^{* * *}$ & $12.22^{* * *}$ & $6.715^{* * *}$ & $8.060 * * *$ \\
\hline $\operatorname{MAE}\left(\times 10^{2}\right)$ & 2.691 & 2.622 & 2.616 & 2.608 & 2.606 & 2.648 & 2.642 \\
\hline DM $t$-stat & & $5.010^{* * *}$ & $5.043^{* * *}$ & $5.081^{* * *}$ & $4.988^{* * *}$ & $2.832^{* * *}$ & $2.826^{* * *}$ \\
\hline Adj. $R^{2}$ of $\mathrm{M}-\mathrm{Z}$ regression & 0.447 & 0.451 & 0.451 & 0.450 & 0.450 & 0.447 & 0.446 \\
\hline 5-day ahead & & & & & & & \\
\hline $\operatorname{RMSE}\left(\times 10^{2}\right)$ & 3.420 & 3.359 & 3.362 & 3.371 & 3.376 & 3.415 & 3.433 \\
\hline DM $t$-stat & & $2.968^{* * *}$ & $2.430 * *$ & 1.629 & 1.296 & 0.174 & -0.377 \\
\hline MAPE (\%) & 39.89 & 35.56 & 35.14 & 34.30 & 34.08 & 37.14 & 36.68 \\
\hline DM $t$-stat & & $8.515^{* * *}$ & $9.150 * * *$ & $10.89 * * *$ & $11.67^{* * *}$ & $5.757^{* * *}$ & $7.268^{* * *}$ \\
\hline $\operatorname{MAE}\left(\times 10^{2}\right)$ & 2.204 & 2.100 & 2.092 & 2.073 & 2.066 & 2.16 & 2.148 \\
\hline DM $t$-stat & & $5.256^{* * *}$ & $5.355^{* * *}$ & $5.363^{* * *}$ & $5.411^{* * *}$ & $2.004^{* *}$ & $2.255^{* *}$ \\
\hline $\operatorname{Adj} . R^{2}$ of $\mathrm{M}-\mathrm{Z}$ regression & 0.561 & 0.573 & 0.572 & 0.571 & 0.570 & 0.559 & 0.554 \\
\hline \multicolumn{8}{|l|}{ 22-day ahead } \\
\hline $\operatorname{RMSE}\left(\times 10^{2}\right)$ & 2.958 & 2.845 & 2.846 & 2.787 & 2.769 & 3.010 & 2.976 \\
\hline DM $t$-stat & & $6.204^{* * *}$ & $6.178^{* * *}$ & $6.806^{* * *}$ & $7.391^{* * *}$ & -1.805 & -0.544 \\
\hline MAPE (\%) & 49.04 & 42.61 & 41.99 & 39.65 & 38.88 & 45.34 & 44.68 \\
\hline DM $t$-stat & & $9.932^{* * *}$ & $10.84^{* * *}$ & $13.36^{* * *}$ & $14.79^{* * *}$ & $5.778^{* * *}$ & $7.181^{* * *}$ \\
\hline MAE $\left(\times 10^{2}\right)$ & 2.392 & 2.206 & 2.196 & 2.107 & 2.079 & 2.354 & 2.308 \\
\hline DM $t$-stat & & $8.030^{* * *}$ & $8.464^{* * *}$ & $10.26^{* * *}$ & $11.34^{* * *}$ & 1.389 & $2.982^{* * *}$ \\
\hline Adj. $R^{2}$ of $\mathrm{M}-\mathrm{Z}$ regression & 0.552 & 0.571 & 0.568 & 0.575 & 0.577 & 0.536 & 0.531 \\
\hline
\end{tabular}


Table 11: Robustness: Subsample volatility forecasting performance: CSI 300 index from 2012 to 2017

This table reports the subsample forecasting performance between the GARCH, GJR-GARCH, and HAR models and the corresponding GARCH-X, GJR-GARCHX, and HAR-X models for the CSI 300 index from January 2012 to September 2017. The root mean square error (RMSE), the mean absolute percentage error (MAPE), and the mean absolute error (MAE) are used. The $t$-statistic of the Diebold and Mariano (1995) (DM) test between forecasts from the benchmark and augmented models, and the adjusted $R^{2}$ of the Mincer-Zarnowitz (M-Z) regression are also reported. ${ }^{*} p<0.1 ;{ }^{* *} p<0.05 ;{ }^{* * *} p<0.01$.

\begin{tabular}{|c|c|c|c|c|c|c|c|}
\hline & \multirow[b]{2}{*}{ Benchmark } & \multicolumn{2}{|c|}{ Equally-weighted } & \multicolumn{2}{|c|}{ Value-weighted } & \multicolumn{2}{|c|}{ Portfolio CSSD } \\
\hline & & CSSD & CSAD & CSSD & CSAD & EW & VW \\
\hline \multicolumn{8}{|l|}{ Panel A: GARCH estimation } \\
\hline $\operatorname{RMSE}\left(\times 10^{2}\right)$ & 8.945 & 8.095 & 8.182 & 8.079 & 8.078 & 8.234 & 8.202 \\
\hline DM $t$-stat & & $3.044^{* * *}$ & $2.572^{* *}$ & $3.189^{* * *}$ & $3.259^{* * *}$ & $2.479^{* *}$ & $2.810^{* * *}$ \\
\hline MAPE (\%) & 144.4 & 126.1 & 122.6 & 130.3 & 126.9 & 127.2 & 128.2 \\
\hline DM $t$-stat & & $5.785^{* * *}$ & $6.553^{* * *}$ & $4.692^{* * *}$ & $5.614^{* * *}$ & $5.460^{* * *}$ & $5.395^{* * *}$ \\
\hline MAE $\left(\times 10^{2}\right)$ & 4.348 & 3.460 & 3.427 & 3.487 & 3.482 & 3.576 & 3.633 \\
\hline DM $t$-stat & & $7.007^{* * *}$ & $6.966^{* * *}$ & $6.729^{* * *}$ & $6.993^{* * *}$ & $6.083^{* * *}$ & $5.956^{* * *}$ \\
\hline Adj. $R^{2}$ of $\mathrm{M}-\mathrm{Z}$ regression & 0.391 & 0.478 & 0.468 & 0.480 & 0.474 & 0.452 & 0.451 \\
\hline \multicolumn{8}{|c|}{ Panel B: GJR-GARCH estimation } \\
\hline $\operatorname{RMSE}\left(\times 10^{2}\right)$ & 8.991 & 7.547 & 7.521 & 7.453 & 7.484 & 7.539 & 7.586 \\
\hline DM $t$-stat & & $5.006^{* * *}$ & $4.903^{* * *}$ & $4.850^{* * *}$ & $4.707^{* * *}$ & $4.825^{* * *}$ & $4.575^{* * *}$ \\
\hline MAPE (\%) & 150.2 & 150.3 & 149.4 & 158.7 & 154.6 & 150.3 & 149.7 \\
\hline DM $t$-stat & & -1.083 & -0.870 & $-2.506^{* *}$ & $-1.737^{*}$ & -1.118 & -1.021 \\
\hline $\operatorname{MAE}\left(\times 10^{2}\right)$ & 4.399 & 3.516 & 3.479 & 3.573 & 3.571 & 3.594 & 3.683 \\
\hline DM $t$-stat & & $6.052^{* * *}$ & $6.106^{* * *}$ & $5.403^{* * *}$ & $5.520^{* * *}$ & $5.448^{* * *}$ & $4.968^{* * *}$ \\
\hline $\mathrm{Adj} . R^{2}$ of $\mathrm{M}-\mathrm{Z}$ regression & 0.153 & 0.549 & 0.553 & 0.556 & 0.547 & 0.543 & 0.534 \\
\hline
\end{tabular}




\begin{tabular}{|c|c|c|c|c|c|c|c|}
\hline \multicolumn{8}{|l|}{ Panel C: HAR estimation } \\
\hline \multicolumn{8}{|l|}{ 1-day ahead } \\
\hline $\operatorname{RMSE}\left(\times 10^{2}\right)$ & 7.141 & 7.120 & 7.119 & 7.120 & 7.111 & 7.133 & 7.119 \\
\hline DM $t$-stat & & 0.457 & 0.379 & 0.635 & 0.873 & 0.290 & 0.727 \\
\hline MAPE (\%) & 54.86 & 52.34 & 52.72 & 54.16 & 53.94 & 53.96 & 53.67 \\
\hline DM $t$-stat & & $4.420 * * *$ & $4.063^{* * *}$ & $2.443^{* * *}$ & $3.588^{* * *}$ & $3.603^{* * *}$ & $3.723^{* * *}$ \\
\hline $\operatorname{MAE}\left(\times 10^{2}\right)$ & 2.567 & 2.504 & 2.500 & 2.535 & 2.547 & 2.546 & 2.565 \\
\hline DM $t$-stat & & $3.417^{* * *}$ & $3.027^{* * *}$ & $2.319^{* *}$ & 1.407 & $1.647^{*}$ & 0.144 \\
\hline Adj. $R^{2}$ of $\mathrm{M}-\mathrm{Z}$ regression & 0.581 & 0.586 & 0.587 & 0.584 & 0.585 & 0.582 & 0.583 \\
\hline \multicolumn{8}{|l|}{ 5-day ahead } \\
\hline $\operatorname{RMSE}\left(\times 10^{2}\right)$ & 5.584 & 5.429 & 5.412 & 5.524 & 5.551 & 5.559 & 5.592 \\
\hline DM $t$-stat & & $1.796^{*}$ & $1.655^{*}$ & 1.053 & 0.766 & 0.447 & -0.177 \\
\hline MAPE (\%) & 51.09 & 46.91 & 47.71 & 49.99 & 49.67 & 49.24 & 48.67 \\
\hline DM $t$-stat & & $3.973^{* * *}$ & $3.453^{* * *}$ & $2.192^{* * *}$ & $3.807^{* * *}$ & $4.353^{* * *}$ & $6.282^{* * *}$ \\
\hline $\operatorname{MAE}\left(\times 10^{2}\right)$ & 2.245 & 2.133 & 2.128 & 2.195 & 2.218 & 2.216 & 2.245 \\
\hline DM $t$-stat & & $3.278^{* * *}$ & $2.896^{* * *}$ & $2.140^{*}$ & 1.313 & 1.243 & -0.019 \\
\hline Adj. $R^{2}$ of $\mathrm{M}-\mathrm{Z}$ regression & 0.601 & 0.619 & 0.621 & 0.605 & 0.604 & 0.601 & 0.599 \\
\hline \multicolumn{8}{|l|}{ 22-day ahead } \\
\hline $\operatorname{RMSE}\left(\times 10^{2}\right)$ & 5.145 & 4.319 & 4.193 & 4.678 & 4.793 & 4.714 & 4.880 \\
\hline DM $t$-stat & & $4.556^{* * *}$ & $4.511^{* * *}$ & $3.194^{* * *}$ & $2.696^{* * *}$ & $3.137^{* * *}$ & $2.149^{* *}$ \\
\hline MAPE $(\%)$ & 65.69 & 56.34 & 59.13 & 68.22 & 70.44 & 65.53 & 67.15 \\
\hline DM $t$-stat & & $3.808^{* * *}$ & $2.849^{* * *}$ & $-1.696^{*}$ & $-3.824^{* * *}$ & 0.111 & $-1.759^{*}$ \\
\hline $\operatorname{MAE}\left(\times 10^{2}\right)$ & 2.495 & 2.081 & 2.065 & 2.263 & 2.332 & 2.285 & 2.372 \\
\hline DM $t$-stat & & $6.412^{* * *}$ & $5.792^{* * *}$ & $4.362^{* * *}$ & $3.454^{* * *}$ & $3.805^{* * *}$ & $2.629^{* * *}$ \\
\hline $\operatorname{Adj} . R^{2}$ of $\mathrm{M}-\mathrm{Z}$ regression & 0.438 & 0.582 & 0.616 & 0.500 & 0.477 & 0.494 & 0.464 \\
\hline
\end{tabular}


Table 12: Robustness: Out-of-sample volatility forecasting performance: SSE composite index

This table reports the out-of-sample forecasting performance between the GARCH, GJR-GARCH and HAR models and the corresponding GARCH-X, GJRGARCH-X, and HAR-X models for the SSE composite index. The root mean square error (RMSE), the mean absolute percentage error (MAPE), and the mean absolute error (MAE) are used. The $t$-statistic of the Diebold and Mariano (1995) (DM) test between forecasts from the benchmark and augmented models, and the adjusted $R^{2}$ of the Mincer-Zarnowitz (M-Z) regression are also reported. ${ }^{*} p<0.1 ;{ }^{* *} p<0.05 ;{ }^{* * *} p<0.01$.

\begin{tabular}{|c|c|c|c|c|c|c|c|}
\hline & \multirow[b]{2}{*}{ Benchmark } & \multicolumn{2}{|c|}{ Equally-weighted } & \multicolumn{2}{|c|}{ Value-weighted } & \multicolumn{2}{|c|}{ Portfolio CSSD } \\
\hline & & CSSD & CSAD & CSSD & CSAD & EW & VW \\
\hline \multicolumn{8}{|l|}{ Panel A: GARCH estimation } \\
\hline $\operatorname{RMSE}\left(\times 10^{2}\right)$ & 6.013 & 5.815 & 5.681 & 5.852 & 5.798 & 5.746 & 5.811 \\
\hline DM $t$-stat & & $6.373^{* * *}$ & $6.536^{* * *}$ & $5.735^{* * *}$ & $3.564^{* * *}$ & $5.650^{* * *}$ & $3.524^{* * *}$ \\
\hline MAPE (\%) & 141.9 & 156.6 & 150.6 & 150.7 & 143.4 & 145.4 & 143.9 \\
\hline DM $t$-stat & & $-10.75^{* * *}$ & $-6.331^{* * *}$ & $-6.825^{* * *}$ & -1.133 & $-2.454^{* * *}$ & -1.607 \\
\hline MAE $\left(\times 10^{2}\right)$ & 3.161 & 3.163 & 3.050 & 3.128 & 2.978 & 3.038 & 3.029 \\
\hline DM $t$-stat & & -0.091 & $4.246^{* * *}$ & 1.631 & $6.746^{* * *}$ & $4.215^{* * *}$ & $4.537^{* * *}$ \\
\hline Adj. $R^{2}$ of $\mathrm{M}-\mathrm{Z}$ regression & 0.376 & 0.410 & 0.431 & 0.397 & 0.396 & 0.412 & 0.396 \\
\hline \multicolumn{8}{|c|}{ Panel B: GJR-GARCH estimation } \\
\hline $\operatorname{RMSE}\left(\times 10^{2}\right)$ & 6.141 & 5.776 & 5.550 & 5.720 & 5.391 & 5.478 & 5.523 \\
\hline DM $t$-stat & & $5.356^{* * *}$ & $6.150^{* * *}$ & $5.737^{* * *}$ & $5.593^{* * *}$ & $5.197 * * *$ & $4.845^{* * *}$ \\
\hline MAPE (\%) & 150.6 & 159.5 & 150.5 & 151.6 & 143.2 & 149.6 & 148.6 \\
\hline DM $t$-stat & & $-5.246^{* * *}$ & 0.048 & -0.576 & $3.681^{* * *}$ & 0.517 & 1.094 \\
\hline $\operatorname{MAE}\left(\times 10^{2}\right)$ & 3.297 & 3.200 & 3.037 & 3.099 & 2.826 & 3.046 & 3.030 \\
\hline DM $t$-stat & & $3.624^{* * *}$ & $7.660^{* * *}$ & $6.368^{* * *}$ & $9.575^{* * *}$ & $5.512^{* * *}$ & $5.528^{* * *}$ \\
\hline Adj. $R^{2}$ of $\mathrm{M}-\mathrm{Z}$ regression & 0.361 & 0.428 & 0.463 & 0.429 & 0.484 & 0.477 & 0.464 \\
\hline
\end{tabular}




\begin{tabular}{|c|c|c|c|c|c|c|c|}
\hline \multicolumn{8}{|l|}{ Panel C: HAR estimation } \\
\hline \multicolumn{8}{|l|}{ 1-day ahead } \\
\hline $\operatorname{RMSE}\left(\times 10^{2}\right)$ & 4.863 & 4.806 & 4.798 & 4.851 & 4.856 & 4.866 & 4.858 \\
\hline DM $t$-stat & & $2.882^{* * *}$ & $2.482^{* *}$ & 0.855 & 0.396 & -0.221 & 0.372 \\
\hline MAPE $(\%)$ & 48.34 & 50.51 & 48.63 & 47.53 & 47.26 & 48.18 & 47.76 \\
\hline DM $t$-stat & & $-6.370 * * *$ & -1.002 & $2.934^{* * *}$ & $3.831^{* * *}$ & 1.117 & $3.287^{* * *}$ \\
\hline $\operatorname{MAE}\left(\times 10^{2}\right)$ & 1.691 & 1.677 & 1.662 & 1.661 & 1.656 & 1.687 & 1.688 \\
\hline DM $t$-stat & & $1.819^{*}$ & $3.226^{* * *}$ & $4.896^{* * *}$ & $5.143^{* * *}$ & 0.783 & 0.571 \\
\hline $\operatorname{Adj} . R^{2}$ of $\mathrm{M}-\mathrm{Z}$ regression & 0.550 & 0.563 & 0.565 & 0.554 & 0.554 & 0.550 & 0.551 \\
\hline \multicolumn{8}{|l|}{ 5-day ahead } \\
\hline $\operatorname{RMSE}\left(\times 10^{2}\right)$ & 3.537 & 3.310 & 3.253 & 3.459 & 3.463 & 3.556 & 3.552 \\
\hline DM $t$-stat & & $5.188^{* * *}$ & $5.061^{* * *}$ & $3.473^{* * *}$ & $2.610^{* * *}$ & -0.974 & -0.880 \\
\hline MAPE (\%) & 41.20 & 45.51 & 41.91 & 40.13 & 39.89 & 40.98 & 39.97 \\
\hline DM $t$-stat & & $-7.960 * * *$ & -1.600 & $2.828^{* * *}$ & $3.348^{* * *}$ & 1.419 & $5.562^{* * *}$ \\
\hline $\operatorname{MAE}\left(\times 10^{2}\right)$ & 1.416 & 1.387 & 1.347 & 1.363 & 1.356 & 1.414 & 1.409 \\
\hline DM $t$-stat & & $2.395^{* *}$ & $4.560^{* * *}$ & $5.644^{* * *}$ & $5.622^{* * *}$ & 0.388 & 1.004 \\
\hline Adj. $R^{2}$ of $\mathrm{M}-\mathrm{Z}$ regression & 0.613 & 0.658 & 0.671 & 0.627 & 0.626 & 0.609 & 0.610 \\
\hline \multicolumn{8}{|l|}{ 22-day ahead } \\
\hline $\operatorname{RMSE}\left(\times 10^{2}\right)$ & 3.273 & 2.667 & 2.482 & 2.923 & 2.876 & 3.183 & 3.236 \\
\hline DM $t$-stat & & $6.263^{* * *}$ & $6.335^{* * *}$ & $6.304^{* * *}$ & $5.822^{* * *}$ & $2.280^{* *}$ & 1.169 \\
\hline MAPE (\%) & 47.02 & 56.57 & 49.38 & 47.37 & 47.88 & 49.48 & 47.77 \\
\hline DM $t$-stat & & $-9.579 * * *$ & $-3.108^{* * *}$ & -0.568 & -1.282 & $-5.691^{* * *}$ & $-2.794^{* * *}$ \\
\hline $\operatorname{MAE}\left(\times 10^{2}\right)$ & 1.514 & 1.414 & 1.317 & 1.387 & 1.376 & 1.511 & 1.515 \\
\hline DM $t$-stat & & $4.395^{* * *}$ & $7.205^{* * *}$ & $8.095^{* * *}$ & $7.337^{* * *}$ & 0.289 & -0.008 \\
\hline Adj. $R^{2}$ of $\mathrm{M}-\mathrm{Z}$ regression & 0.490 & 0.641 & 0.685 & 0.564 & 0.575 & 0.508 & 0.493 \\
\hline
\end{tabular}

